\title{
Histone modifications during the life cycle of the brown alga Ectocarpus
}

Simon Bourdareau ${ }^{1}$, Leila Tirichine ${ }^{2}$, Bérangère Lombard ${ }^{3}$, Damarys Loew $^{3}$, Delphine Integrative Biology of Marine Models, Station Biologique de Roscoff, CS 90074, F-29688, Roscoff, France, ${ }^{2}$ Université de Nantes, CNRS, UFIP, UMR 6286, F-44000 Nantes, France, ${ }^{3}$ Institut Curie, PSL Research University, Centre de Recherche, Laboratoire de Spectrométrie de Masse Protéomique, 26 rue d’Ulm, 75248 Cedex 05 Paris, France. *Authors for correspondence (cock@sb-roscoff.fr; coelho@sb-roscoff.fr)

\section{Abstract}

Background: Brown algae evolved complex multicellularity independently of the animal and land plant lineages and are the third most developmentally complex phylogenetic group on the planet. An understanding of developmental processes in this group is expected to provide important insights into the evolutionary events necessary for the emergence of complex multicellularity. Here we have focused on mechanisms of epigenetic regulation involving posttranslational modifications (PTMs) of histone proteins.

Results: A total of 47 histone PTMs were identified, including a novel mark H2AZR38me1, but Ectocarpus lacks both H3K27me3 and the major polycomb complexes. ChIP-seq identified PTMs associated with transcription start sites (TSSs) and gene bodies of active genes, and with transposons. H3K79me2 exhibited an unusual pattern, often marking large genomic regions spanning several genes. TSSs of closely spaced divergently transcribed gene pairs shared a common nucleosome depleted region and exhibited shared histone PTM peaks. Overall, patterns of histone PTMs were stable through the life cycle. Analysis of histone PTMs at generation-biased genes identified a correlation between the presence of specific chromatin marks and the level of gene expression.

Conclusions: The overview of histone PTMs in the brown algae presented here will provide a foundation for future studies aimed at understanding the role of chromatin modifications in the regulation of brown algal genomes. 
Keywords: brown algae, ChIP-seq, chromatin, Ectocarpus, gametophyte, histone modification, life cycle, multicellularity, polycomb complex, sporophyte

\section{Introduction}

Very few eukaryotic lineages have independently evolved complex multicellularity and the brown algae are of particular interest as the third most developmentally complex lineage after animals and land plants. The size and complexity attained by some brown algae is illustrated by the giant kelp Macrocystis, which can reach up to 50 metres in length.

The deployment of developmental programs and the establishment of different cell fates in complex multicellular organisms implies the acquisition of different epigenetic states in different cell types. A number of mechanisms underlie the establishment and maintenance of epigenetic states. These include, for example, cell signalling and regulation of gene transcription but another important factor is chemical modification of chromatin. In particular, histones have been shown to undergo a broad range of different post-translational modifications (PTMs) involving the addition of various chemical moieties to multiple amino acid residues, particularly within the unstructured amino-terminal "tails" of these proteins [1]. These modifications affect chromatin function either by directly modifying interactions between the different components of the nucleosome or via the action of proteins that bind to specific histone modifications and effect specific tasks. In this manner, histone PTMs act as a "histone code", mediating the establishment and maintenance of different epigenetic states across the genome.

Epigenetic processes not only allow cells that carry the same genomic information to assume different functions in different parts of a multicellular organism but they also allow temporal changes, i.e. establishment of different cellular functions at different stages of the life history. This latter aspect is particularly important in organisms that have complex life cycles. For example, many brown algae have haploid-diploid life cycles involving an alternation between two different organisms, the sporophyte and the gametophyte, often with very distinct bodyplans [2]. These life cycles imply complex regulation of chromatin but, at present, very little is known about the role of histone PTMs, for example, in the regulation of developmental and life cycle processes in the brown algae.

The filamentous alga Ectocarpus is being used as a model system to study brown algal developmental biology [3-7]. Ectocarpus has a haploid-diploid life cycle involving an alternation between a gametophyte, which is usually haploid, and a sporophyte, which is usually diploid. However, there is clear evidence that the identity of each life cycle generation is not 
determined by its ploidy because haploid sporophytes (partheno-sporophytes) can be produced by parthenogenetic development of haploid gametes [8,9] and diploid gametophytes can be constructed using mutants that are unable to deploy the sporophyte developmental pathway $[3,7]$. These observations indicate that epigenetic processes play an important role during the Ectocarpus life cycle. Recent work has shown that the deployment of the sporophyte program requires two different three amino acid loop extension homeodomain transcription factors (TALE HD TFs), OUROBOROS (ORO) and SAMSARA (SAM) [7]. Remarkably, TALE HD TFs appear to have been recruited convergently to regulate sporophyte development in both the brown algal and the land plant lineages [7]. In land plants, the PRC2 polycomb complex has also been implicated in life cycle regulation [10-17], indicating that chromatin modification processes play an important role in life cycle regulation in that lineage. Chromatin modification has been proposed to play a similar role in the brown algae [2] but this hypothesis has not been investigated experimentally.

In this study, we have carried out a broad census of histone PTMs in Ectocarpus chromatin and have developed a method to evaluate the genome-wide distribution of specific histone PTMs in this species. Application of this method allowed the identification of histone PTMs associated with transcriptional start sites (H3K4me2, H3K4me3, H3K9ac, H3K14ac and $\mathrm{H} 3 \mathrm{~K} 27 \mathrm{ac}$ ) and gene bodies (H3K36me3) of actively transcribed genes and a histone PTM associated with transposons and repetitive sequences (H4K20me3). We also show that H3K79me2 often marks extensive regions spanning several genes and suggest some possible functions for this PTM. Overall, genome-wide histone PTM patterns were found to remain stable following transition between the sporophyte and gametophyte generations of the life cycle, consistent with the observation that only $4 \%$ of genes exhibited a significant level of generation-biased expression. Analysis of generation-biased genes allowed changes in chromatin state (combinations of histone PTMs) to be correlated with changes in gene expression.

\section{Results}

\section{Ectocarpus histones and histone modifier enzymes}

Analysis of the Ectocarpus genome sequence [18] identified 34 core histone and nine H1 histone genes (Additional file 5: Table S1). Four of the core histone genes are predicted to encode variant forms, including probable CenH3, H2A.X and H2A.Z proteins. All nine H1 histone genes appear to encode bona fide $\mathrm{H} 1$ proteins and are not members of related families 

on H2A.Z; Fig. 1b). file 2: Figure S1).

such as the plant GH1-HMGA or GH1-Myb families [19]. All but eight of the histone genes were located in five gene clusters on chromosomes 4, 7 and 26 and on an unmapped scaffold (sctg_442). The organisation of the clusters suggests multiple duplication, rearrangement and fragmentation of an ancestral cluster with the organisation H4, H1, H3, H2B, H2A (Additional

$$
\text { acetyltransferases and methyltransferases, and predicted deacetylase and demethylase enzymes }
$$
(Additional file 6: Table S2). Most of the acetyltransferases were sufficiently similar to wellcharacterised homologues to allow prediction of their target residues but the methyltransferases tended to be less conserved at the sequence level and, in many cases, had novel domain structures. Direct functional information, for example based on mutant analysis, will therefore be necessary to investigate the specificity of the Ectocarpus methyltransferases.

\section{Identification of histone PTMs in Ectocarpus}

Histone PTMs were detected using mass spectrometry of enzyme-digested histone preparations. In addition, a broad range of commercially available antibodies were tested against Ectocarpus histone preparations on immunoblots to further confirm the presence of a subset of the PTMs identified by mass spectrometry. A total of 47 PTMs of core and variant histones were detected in Ectocarpus (Fig. 1a, Additional file 3: Figure S2). Six of these marks were only detected by immunoblotting and should therefore be treated with caution (marked with an asterisk in Fig. 1a, Additional file 7: Table S3). Note that two of these PTMs, H3K9me2 and H3K9me3, were also not detectable using mass spectrometry in Arabidopsis but have been detected using immunoblotting [20,21]. Figure S3 (Additional file 4) shows immunoblots that detected a weak signal for these two PTMs in Ectocarpus chromatin.

Most of the histone PTMs detected in Ectocarpus have been reported previously in species from one or more of the land plant, animal or fungal lineages, either at exactly the same position or at an equivalent position in the corresponding protein (Fig. 1b, Additional file 7: Table S3). However, a number of marks have only been described so far in stramenopiles. Of these, some PTMs such as acetylation of lysines nine and 15 of H2A.Z were detected in both Ectocarpus and the diatom P. tricornutum [22], whereas others were detected only in the 
135 To investigate the functions of histone PTMs in Ectocarpus, we analysed the distribution of

136 eight selected marks across the genome using chromatin immunoprecipitation and sequencing 137 (ChIP-seq). The PTMs analysed were H3K4me2, H3K4me3, H3K9ac, H3K14ac, H3K27ac, 138 H3K36me3, H3K79me2 and H4K20me3 (Fig. 2). Five of these PTMs, H3K4me2, H3K4me3, $139 \mathrm{H} 3 \mathrm{~K} 9 \mathrm{ac}, \mathrm{H} 3 \mathrm{~K} 14 \mathrm{ac}$ and $\mathrm{H} 3 \mathrm{~K} 27 \mathrm{ac}$, were preferentially associated with the transcription start 140 sites (TSSs) of genes but tended to be depleted from gene bodies (Fig. 2a,b,c,d). Genome-wide 141 patterns of these five PTMs exhibited a range of levels of positive correlation (Pearson's r 0.13 142 to 0.86; Fig. 2e), indicating that they tended to be co-localised in the genome. Similar PTM 143 patterns were detected at protein-coding and lncRNA genes (Fig. 2c), suggesting that histone 144 PTMs may be used in a similar manner to regulate these two types of gene. For each of the five TSS-associated PTMs a peak was detected within 500 bp of the TSS for between $77 \%$ and $83 \%$ 146 of the genes in the genome. For $\mathrm{H} 3 \mathrm{~K} 4 \mathrm{me} 2$, a pair of adjacent peaks was detected, one on each 147 side of the TSS (Fig. 2b,c). Genome-wide, peaks of H3K4me2, H3K4me3, H3K9ac, H3K14ac 148 and H3K27ac marks were associated with between 13, 416 and 14,423 of the 17,406 genes. We 149 noted a strong positive correlation between gene expression level, measured in transcripts per 150 million (TPM) and the strength of mapping of each mark to TSSs (Fig. 3). Taken together, these 151 observations indicate a strong association of H3K4me2, H3K4me3, H3K9ac, H3K14ac and H3K27ac with transcriptionally active genes in Ectocarpus.

153 The three remaining PTMs, H3K36me3, H3K79me2 and H4K20me3, were depleted 154 from TSSs (Fig. 2). H3K36me3, which was detected at 12,863 genes (74\% of the genome), was 155 most strongly associated with gene bodies and was depleted from both TSSs and transcription 156 end sites (TESs). As observed for the TSS-localised PTMs discussed above, presence of 157 H3K36me3 on gene bodies was positively correlated with expression, indicating that this mark is also associated with gene activation (Fig. 3).

H4K20me3 peaks were detected principally in the non-coding part of the genome 160 (intergenic regions and introns; Fig. 2a) and occurred preferentially in intergenic regions or 161 introns that also contained a transposon (Pearson's $\chi^{2}$ test with Yates' continuity correction $\mathrm{p}$ 162 value $<2.2 \mathrm{e}-16$ for both introns and intergenic regions). Indeed, almost all (94.6\%) of the 163 H4K20me3 peaks co-localised with either a transposon or a region of short repeated sequence.

164 The distribution of H4K20me3 was therefore consistent with it playing a role in the regulation of inserted transposons, possibly in the silencing of these elements. H4K20me3 peaks were associated with all types of transposon, including both class I (RNA) and class II (DNA)

167 transposons (Additional file 5: Table S4). The occurrence of H4K20me3 in introns was not 168 unexpected because introns make up approximately $40 \%$ of the Ectocarpus genome [23], and 
169 therefore represent a significant proportion of the non-coding fraction of the genome.

170 Moreover, $44.0 \%$ of the transposons (repeated elements $\geq 400 \mathrm{bp}$ ) in the genome are located in 171 introns.

172 Genes marked with H4K20me3 tended to have fewer exons, to be longer and to have 173 lower levels of expression than genes without a H4K20me3 peak (Fig. 4a,b,c). The inverse 174 relationship between the presence of H4K20me3 and gene expression level (Fig. 3) could be 175 interpreted as indicating a role in gene regulation but, given the co-localisation of this PTM 176 with transposon sequences, a more likely explanation is that the observed effect on gene expression was an indirect effect of silencing of intronic transposon sequences. Interestingly, genes that were marked with H4K20me3 were significantly less strongly marked with the TSSassociated PTMs H3K4me2, H3K4me3, H3K9ac, H3K14ac and H3K27ac (Fig. 4d). Several

180 hypotheses could be proposed to explain this observation. If the presence of H4K20me3 within

181 a gene directly causes a reduction in the abundance of TSS-associated PTMs, this may 182 constitute part of the mechanism that mediates the repressive effect of H4K20me 3 on gene 183 expression. Alternatively, it is also possible that the reduction in the abundance of TSSassociated PTMs is an indirect consequence of H4K20me3-induced repression of gene expression.

\section{The genome is partitioned into H3K79me2-marked and H3K79me2-depleted regions}

H3K79me2 exhibited an unusual distribution pattern. This PTM was detected throughout the genome, often in large, discrete, continuously marked regions of several kilobases separated by H3K79me2-depleted regions (Fig. 5a, Additional file 4: Figure S4). Together the H3K79me2 regions covered $74.5 \mathrm{Mbp}, 37.2 \%$ of the genome. About a third (36.6\%) of the H3K79me2 regions were longer than $5 \mathrm{kbp}$ and many of these regions spanned more than one gene (on average, H3K79me 2 regions of $>5 \mathrm{kbp}$ contained 1.85 genes). The borders of the long H3K79me2 regions tended to be localised near a TSS or a TES. When H3K79me2 regions of $>5 \mathrm{kbp}$ were considered, $49.3 \%$ of the borders were located within a kilobase of a TSS or a TES and a Bonferonni-adjusted Wilcoxon test indicated that the borders were significantly closer to

197 the nearest TSS or TES than they were to random anchor points in the genome (Additional file 4: Figure S5).

Comparison of ChIP-seq data for the sporophyte and gametophyte generations of the life cycle indicated that the $\mathrm{H} 3 \mathrm{~K} 79 \mathrm{me} 2$ regions were stably maintained throughout the life cycle. Only $0.3 \%$ or $1.2 \%$ of $\mathrm{H} 3 \mathrm{~K} 79 \mathrm{me} 2$ regions longer than $5 \mathrm{kbp}$ were detected uniquely in

202 the sporophyte or the gametophyte generation, respectively. 
The H3K79me2 regions were strongly associated with peaks of H4K20me3 (Fig. 5a,b; Additional file 4: Figure S4). Consistent with the co-localisation of the two PTMs, genes within H3K79me2 regions were significantly shorter, possessed fewer introns and their transcripts were less abundant on average than genes that were outside H3K79me2 regions (Fig. 4c-e). The TSSs of genes within the H3K79me2 regions were also significantly less strongly marked by H3K4me2, H3K4me3, H3K9ac, H3K14ac and H3K27ac (Fig. 4f) and there was a negative correlation between gene expression level (measured in TPM) and the quantitative presence of H3K79me2 over genes (Fig. 3). To determine whether the association of H3K79me2 with reduced levels of gene expression and reduced deposition of TSS-localised PTMs was an indirect consequence of the co-localisation of this mark with H4K20me3, we analysed loci (Fig. 5b) where the two PTMs occurred independently of each other (Additional file 4: Figure S6). This analysis indicated that both H3K79me2 and H4K20me3 were associated with reduced levels of gene expression and reduced deposition of TSS-localised PTMs, even when one PTM was present independently of the other. Moreover, the effects of H3K79me2 and H4K20me3 on gene expression and on the deposition of TSS-localised PTMs were additive when both PTMs were present at the same locus, i.e. levels of gene expression and TSS-localised PTMs were even lower when both PTMs were present. Therefore, like H4K20me3, H3K79me2 appears to be associated with the repression of gene expression. However, based on a similar argument to that proposed for H4K20me3 above, the organisation of deposition of H3K79me2 across blocks of contiguous genes (Fig. 5) does not appear to be consistent with a direct role in gene regulation and we therefore favour the hypothesis that, as proposed for H4K20me3, the effect of $\mathrm{H} 3 \mathrm{~K} 79 \mathrm{me} 2$ on gene regulation is an indirect consequence of the involvement of this PTM in another, currently unknown, role in chromatin homeostasis. from approximately 4,244,200 to 4,547,200) that is closely related to the Ectocarpus phaeovirus EsV-1. The inserted virus has been shown to be transcriptionally silent [18,23]. A large H3K $79 m e 2$ region of about $0.42 \mathrm{Mbp}$ was detected that spanned the entire inserted viral genome (Additional file 4: Figure S7). Chromatin within this H3K79me2 region was also marked with H4K20me3 but the other histone PTMs assayed were depleted from the inserted viral genome (Additional file 4: Figure S7).

\section{Overlapping TSS regions of divergently transcribed gene pairs}

235 One unusual feature of the Ectocarpus genome, compared to genomes of similar size, is that 236 there is a relatively strong tendency for adjacent genes to be transcribed from opposite strands 
of the DNA helix [23]. Consequently, the genome contains many divergently transcribed gene pairs. To investigate the effect of this pattern of gene organisation on the chromatin characteristics of TSSs, we searched for pairs of adjacent genes located on the same sequence scaffold. This search identified 10,399 TSS-adjacent intergenic regions and $61.7 \%$ of the genes flanking these regions were part of a divergently transcribed gene pair. The intergenic regions of divergently transcribed gene pairs were significantly shorter than those of tandem gene pairs (median 409 and 2293, respectively, Wilcoxon test, $p$-value $<2 \mathrm{e}^{-16}$; Fig. 6a). When the intergenic regions of divergent gene pairs were shorter than about $600 \mathrm{bp}$, the two TSS chromatin regions overlapped and shared the same nucleosome depleted region (NDR) based on micrococcal nuclease digestion data (Fig. 6a). This overlap correlated with the presence of double peaks for the PTMs H3K4me3, H3K9ac, H3K14ac and H3K27ac, one on each side of the TSS (Fig. 6a,b). For H3K4me2, which was detected as a double peak at most individual TSSs (Fig. 2b), the two peaks were further apart at the overlapping TSSs of divergent gene pairs than they were at the single intergenic TSSs of tandem gene pairs (Fig. 6a,b). Therefore, the pattern of PTMs also indicated that the TSSs of proximate divergent genes are located within a shared chromatin domain. Signals for all five of the above PTMs were significantly stronger for divergent than for tandem gene pairs (Fig. 6c, measured at the TSS of the second gene of the gene pair, see schema in Fig. 6a). This difference appeared to be due to the overlap of the two divergent TSS regions as the signal markedly increased for intergenics of divergent gene pairs that were shorter than $1 \mathrm{kbp}$ (Fig. 6c). Consistent with this observation, no significant difference was detected between the median expression levels of divergent and tandem genes (Fig. 6d). Note that transcript abundances were not correlated for the two genes of a divergent gene pair (Pearson coefficients were 0.042 for all the divergent pairs and 0.054 for divergent pairs closer than $600 \mathrm{bp}$; Additional file 4: Figure S8), despite the presence of a shared chromatin domain at the TSSs and correlated histone PTM signals immediately downstream of each TSS when divergent genes were closer than 600 bp (Additional file 4: Figure S8).

\section{Histone PTM patterns during the Ectocarpus life cycle}

265 To relate patterns of histone modification to changes in gene expression during the Ectocarpus life cycle, ChIP-seq analysis was used to compare the distributions of histone PTMs during the sporophyte and gametophyte generations. Overall, the distribution of PTMs was stable between the two life cycle generations. For example, the six PTMs associated with actively expressed genes, H3K4me2, H3K4me3, H3K9ac, H3K14ac, H3K27ac and H3K36me3, were either stably present or stably absent for between $82.7 \%$ and $97.1 \%$ of the 17,406 genes genome-wide, 
depending on the PTM. This analysis indicated that there were not any major, genome-wide changes in patterns of histone PTMs associated with alternation between life cycle generations. To focus more specifically on changes in patterns of histone PTMs associated with life-cyclerelated changes in gene expression, we analysed the presence and absence of marks at genes that were differentially regulated between the two life cycle generations (Fig. 7a).

A comparison of gene expression patterns in the sporophyte and gametophyte, based on RNA-seq data generated using the same biological samples as were used for the ChIP-seq analysis, identified 774 genes that exhibited a generation-biased pattern of expression (padj $<0.05$, fold change $>2, T P M>1$; Fig. 7a, Additional file 5: Table S5). We will refer to these 774 genes as generation-biased genes (GBGs). Analysis of the predicted functions of the GBGs using a system of manually-assigned functional categories [7], indicated significant enrichment in several functional categories, in particular in cell wall and extracellular proteins and proteins of unknown function ( $\chi^{2}$ test padj $3.73 \mathrm{e}^{-40}$ and $1.56 \mathrm{e}^{-5}$, respectively; Table S6). Prediction of subcellular location using Hectar [24], indicated that the GBG protein set was also significantly enriched in secreted proteins ( $\chi^{2}$ test, $2.20 \mathrm{e}^{-27}$; Table S7). These observations are consistent with a recent analysis using an independently identified set of GBGs [7] and suggest possible important roles for the cell wall and intercellular interactions in the specific functions of the two generations of the life cycle. Interestingly, this set of differentially expressed genes was significantly enriched in long non-coding RNAs (lncRNAs; Additional file 5: Table S8; $\chi^{2}$ test, $1.52 \mathrm{e}^{-15}$ ) and 19 of the 72 differentially expressed lncRNAs were adjacent to a differentially expressed protein-coding GBG (including four lncRNA/protein-coding gene pairs with overlapping transcripts; Additional file 5: Table S8). In most cases (84\%), the lncRNA and its adjacent protein-coding gene were co-ordinately upregulated during the same generation of the life cycle (Table S9). These observations suggest a possible role for lncRNAs in the regulation of adjacent genes in Ectocarpus.

To analyse changes in histone PTMs at GBGs between life cycle generations, 16 chromatin states were defined based on different combinations of four TSS-localised PTMs that exhibited clear patterns of presence and absence: H3K4me2, H3K4me3, H3K9ac and H3K27ac (Fig. 7b). In most cases when GBGs changed chromatin state during the transition between the two generations, increased transcript abundance was correlated with acquisition of additional activation-associated PTMs (76.1\% of the GBGs that changed chromatin state). However, the majority of GBGs (61.1\%) did not change chromatin state between generations, although we noted that most of these genes $(81.4 \%)$ were marked with all four activation-associated PTMs during both generations. Taken together, these observations are consistent with a correlation 
between the presence of the four TSS-localised marks and gene activation but indicate that additional mechanisms may be necessary to induce differential gene expression. Therefore, if the histone PTMs have role in regulating transcription, this role would most likely be to facilitate or potentiate transcription rather than directly activating gene transcription. Note, however, that it is also possible that some or all of the observed histone PTM modifications were a consequence, rather than a cause, of transcription.

We detected more sporophyte-biased (503) than gametophyte-biased (271) genes $\left(\chi^{2}\right.$ test, $\left.7.49 \mathrm{e}^{-17}\right)$ and the former were significantly more strongly upregulated than the latter $(4.2$ and 2.8 mean $\log 2$ TPM fold changes, respectively; Kruskal-Wallis rank sum test $p$-value $=$ $\left.4.0 \mathrm{e}^{-11}\right)$. Overall, sporophyte-biased and gametophyte-biased genes showed similar patterns of transitions to new chromatin states (Spearman's rank correlation rho $0.61, p$-value $=0.011$ ) However, the sporophyte-biased genes exhibited a stronger tendency to switch to chromatin state 1 (presence of all four activation-associated PTMs) than the gametophyte-biased genes (74.8\% compared with $26.4 \%$ of chromatin state transitions, respectively; z score 7.7857 , $p<0.00001)$. This observation is consistent with the larger fold changes in transcript abundance (TPM) observed for sporophyte-biased genes as transitions to chromatin state 1 were associated with significantly larger fold changes than transitions to other states (Wilcoxon test, p-value $<0.0078$ for all GBGs). We also noted that the GBGs that exhibited the highest fold changes also exhibited a stronger tendency to change chromatin state between generations (Fig. 7c). This was true for both sporophyte-biased and gametophyte-biased genes.

\section{Ectocarpus lacks polycomb repressive complexes}

327 Polycomb repressive complexes have been shown to play important roles in the regulation of a broad range of developmental processes in both animals and land plants $[25,26]$ and a key role has been proposed for Polycomb repressive complex 2 (PRC2) in the regulation of life cycle transitions in both Arabidopsis [10,12-15] and the moss Physcomitrella patens [16,17]. However, in contrast to the conservation and functional importance of these complexes in the land plant and animal lineages, a homology search failed to identify the core proteins of PRC2 in the Ectocarpus genome, and a similar result was obtained for PRC1 ([2]; Fig. 8, Additional file 5: Table S10). This analysis did identify an orthologue of the WD domain protein RbAp48 but this protein is also known to be a key component of other regulatory complexes in the cell, such as CAF-1, NuRD and NURF [27]. Moreover, analysis of the Cladosiphon okamuranus [28], Nemacystus decipiens [29] and Saccharina japonica [30] genomes indicated that they too 
of PRC complexes being a general feature of the brown algae (Table. S10). We cannot rule out the possibility that the brown algae possess highly diverged versions of the PRC2 and PRC1 complexes but this would seem unlikely as the evolutionary time separating brown algae from plants and animals is similar to that separating the latter two lineages. Moreover, orthologues

343 of all the PRC2 and PRC1 core components were found in the genome of the diatom 344 Phaeodactylum tricornutum, which also belongs to the stramenopile lineage ([31]; Additional 345 file 5: Table. S10). Analysis of the limited number of complete genomes available for the stramenopiles indicated that PRC1 was lost after divergence from the diatoms and PRC2 at a later stage after divergence from the Pelagophyceae (Fig. 8b). Absence of PRC2 in Ectocarpus was supported by the fact that the mass spectrometry analysis did not detect any evidence of tri-methylation of H3K27. Histone immunoblots with an antibody raised against H3K27me3 (Additional file 5: Table S11) weakly detected a protein of the expected size but the signal was only detected after a lengthy exposure (see legend to Additional file 4: Figure S3) and when this antibody was employed in a ChIP-seq experiment we did not detect any specific chromatin immunoprecipitation (data not shown). Similarly, an antibody raised against H2AK119ub did not detect this histone PTM in Ectocarpus chromatin (Additional file 3: Figure S9). Therefore, taken together, these analyses indicated that Ectocarpus lacks the PRC2 and PRC1 polycomb complexes and, consequently, the histone modifications mediated by these complexes, trimethylation of H3K27 and mono-ubiquitination of H2AK119.

\section{Discussion}

\section{Histone post-translational modifications in a multicellular brown alga}

Brown algae are the third most developmentally complex phylogenetic group on the planet and include members whose bodyplans rival those of land plants in their cellular and developmental complexity. However, compared to animals and land plants, many aspects of brown algal developmental biology are still very poorly understood, including epigenetic regulatory mechanisms. The objective of this study was to provide a comprehensive overview of histone

367 PTMs in the model brown alga Ectocarpus and to investigate the relationship between patterns of key PTMs across the genome and the developmental programs that mediate alternation between the sporophyte and gametophyte generations during this seaweed's life cycle.

Mass spectrometry analysis of Ectocarpus histone preparations demonstrated that brown algal histones are subject to a broad range of PTMs. Most of the modifications detected had been reported previously for histones of organisms from other eukaryotic supergroups, such 
as the land plants within the Archaeplastida or animals and fungi from the Opisthokonta.

374 However, the analysis also confirmed some stramenopile-specific histone PTMs such as H2A.ZK9ac and H2A.ZK15ac and detected a previously unreported (and therefore possibly brown-algal-specific) modification, H2A.ZR38me1. Overall, however, this study confirmed the conclusion, based on an analysis of diatom histone PTMs [22], that a large number of histone PTMs detected in other eukaryotic supergroups are conserved in the stramenopiles. This conclusion is consistent with the observation that histone molecules have been highly conserved during eukaryotic evolution [32,33] and with evidence that many of the proteins involved in post-translational modification of histones can be traced back to the last eukaryotic common ancestor [34]. Indeed, genes encoding histone modifying enzymes with highly conserved domain structures and domain sequences, such as the histone acetyltransferases, were detected in the Ectocarpus genome. For other families, it was difficult to assign predicted proteins to specific functions due to sequence divergence. Experimental analysis of protein function will therefore be necessary to identify the specific writers and readers of many histone PTMs in brown algae.

The Ectocarpus genome does not appear to encode the core components of the polycomb complexes PRC1 and PRC2. Absence of polycomb complexes in a complex multicellular organism may seem surprising from the perspective of animal and land plant model systems but the components of PRC2 are known to exhibit a patchy distribution across the diverse eukaryotic supergroups [35], indicating that they have been repeatedly lost over evolutionary time. In this respect, the absence of polycomb complexes in brown algae represents a striking example of how comparative analysis of groups that have evolved complex multicellularity independently of plants and animals can be used to test the degree to which specific genetic systems (in this case polycomb regulation) have been essential for the evolution of complex multicellularity.

Analysis of ChIP-seq data allowed inferences to be made about the possible functional roles of eight histone PTMs in brown algae. H3K4me2, H3K4me3, H3K9ac, H3K14ac and $\mathrm{H} 3 \mathrm{~K} 27 \mathrm{ac}$ were all detected predominantly at TSSs and the degree to which genes were marked with these PTMs was proportional to their level of expression (transcript abundance), suggesting a role in promoting or facilitating gene transcription. Note, however, that we cannot exclude the opposite hypothesis, that deposition of these PTMs is promoted by gene transcription.

Further evidence for a correlation between gene expression and the presence of the five TSS PTMs was provided by a comparative analysis of chromatin states at GBGs between life 
cycle generations, which indicated a broad correlation between accumulation of $\mathrm{H} 3 \mathrm{~K} 4 \mathrm{me} 2$, H3K4me3, H3K9ac and H3K27ac at the TSS and increased expression of GBGs during the life cycle. However, patterns of histone PTMs at TSSs were not strictly correlated with gene expression indicating that, if these marks do facilitate transcription, they are not sufficient alone to induce gene expression. This conclusion was supported by a genome-wide analysis of closely spaced $(<600 \mathrm{bp}$ ) pairs of divergently transcribed genes, which showed that the TSS regions of gene pairs overlapped but the two genes were nonetheless independently regulated. At present, it is not clear what processes might be necessary, in addition to the deposition of histone PTMs at the TSS, to induce gene expression in Ectocarpus, but these could include, for example, the presence of specific transcription factors and the transcription machinery or the presence of additional histone PTMs, including alternative acyl marks such as propionylation, butyrylation and crotonylation which have been shown to stimulate transcription in cell-free assays [36].

Peaks of H3K4me2, H3K4me3, H3K9ac, H3K14ac and H3K27ac are detected near the TSSs of active genes in both animals and land plants and all of these marks have been associated with active gene expression in both lineages ([37-48]; with the possible exception of $\mathrm{H} 3 \mathrm{~K} 4 \mathrm{me} 2$, which may represent a repressive mark on plants; [48,49]). Overall, therefore, these five histone PTMs appear to have similar roles associated with gene activation at promoters in animals, land plants and brown algae, indicating that at least part of the "histone code" may be universal and therefore have a very deep evolutionary origin.

H3K36me3 marked gene bodies and was absent from TSSs and TESs but its presence was also positively correlated with the level of gene expression. H3K36me3 also marks the bodies of active genes in both animals and land plants, although its distribution along the gene body differs in the two lineages. In Arabidopsis and rice a strong peak was observed at the 5' end of the gene $[44,47,50]$, whereas strong signals have been reported at the 3 ' ends [51] and over exons [52] of animal genes. H3K36me3 is catalysed by SETD2, which is associated with Pol II and is therefore directly linked to transcript elongation [53]. H3K36me3 has also been shown to be involved in alternative splicing in animals and plants [54,55]. The position of H3K36me3 within Ectocarpus genes and the positive correlation with transcript abundance are consistent with an evolutionarily conserved role associated with transcript elongation.

H4K20me3, was associated with transposons and repeat sequences, both between and within genes. The presence of this mark at intronic transposons was inversely correlated with levels of gene expression but its effect on gene expression may be indirect, for example as a consequence of silencing intronic transposons. The distribution of H4K20me3 suggests a similar role to that observed in animals, where H4K20me3 is enriched at transposons and in 
heterochromatin [56-58] and where it has been shown to repress transposons [58]. Note that H4K20me3 appears to have a different role in land plants as it localises to euchromatin and is associated with transcriptional activation [59].

Heterochromatin is marked by methylation of lysine 9 of histone $\mathrm{H} 3$ in animals and land plants [60]. H3K9me3 is the most abundant heterochromatin marker in animals $[61,62]$. In plants, heterochromatin is silenced by a feedback loop involving H3K9me2 and DNA methylation [63], whereas $\mathrm{H} 3 \mathrm{~K} 9 \mathrm{me} 3$ is associated with euchromatin and appears to have a different function [50]. $\mathrm{H} 3 \mathrm{~K} 9 \mathrm{me} 2$ and $\mathrm{H} 3 \mathrm{~K} 9 \mathrm{me} 3$ were detected in Ectocarpus but appear to be present at low abundance and ChIP-seq profiling did not provide any exploitable information about the distribution of these PTMs (unpublished results, data available at NCBI Gene Expression Omnibus accession GSE146369). More sensitive analysis methods will be necessary to investigate the roles of $\mathrm{H} 3 \mathrm{~K} 9 \mathrm{me} 2$ and $\mathrm{H} 3 \mathrm{~K} 9 \mathrm{me} 3$ in brown algae but it is possible that other PTMs, such as H4K20me3 and H3K79me3, carry out at least some of the functions that have been attributed to these PTMs in other lineages.

H3K79me2 exhibited an unusual distribution pattern, marking discrete regions of the genome that often spanned multiple genes. The function of the H3K79me2 is not clear, although H3K79me2-marked regions were strongly correlated with the presence of H4K20me3 and commonly included transposons $(88.6 \%$ of $\mathrm{H} 3 \mathrm{~K} 79 \mathrm{me} 2$ regions of $>5 \mathrm{kbp}$ included a $\geq 400 \mathrm{bp}$ repeated element). As observed for H4K20me3, the presence of $\mathrm{H} 3 \mathrm{~K} 79 \mathrm{me} 2$ was correlated with repression of gene expression (lower levels of transcript abundance). Interestingly, genes marked with both $\mathrm{H} 3 \mathrm{~K} 79 \mathrm{me} 2$ and H4K20me3 were expressed at significantly lower levels than genes marked with only one of the two PTMs, indicating that the mechanisms linking H3K79me 2 and H4K20me3 with gene repression act independently.

Taken together, the above observations would be consistent with a role for H3K79me2 in the silencing of repeated elements (based on a similar argument to that proposed above for $\mathrm{H} 4 \mathrm{~K} 20 \mathrm{me} 3$ ). If H3K79me2 does have a role in the silencing of transposons, it is not clear why the H3K79me2 regions often cover much larger regions than the transposon(s) itself. One possible explanation may be that the regions extend to neighbouring TSSs in order to regulate transcriptional activity in a genomic region containing a transposon. We also noted that H3K79me2 tended to mark convergent gene pairs, even in regions that contained little repeated sequence. A possible additional role of $\mathrm{H} 3 \mathrm{~K} 79 \mathrm{me} 2$ at these loci may be to regulate transcription in some manner to limit or respond to the formation of double-stranded RNA due to transcript overlap. Such double-stranded RNA could be problematic within the cell if it activates small 
RNA pathways but note that an earlier analysis did not find any evidence that convergent gene pairs were a preferential source of sRNAs in Ectocarpus [64].

The distribution pattern observed for H3K79me2 in Ectocarpus is very different from the pattern observed in animals, where H3K79me2 marks the 5' part of the gene body as part of a mutually exclusive pattern with $\mathrm{H} 3 \mathrm{~K} 36 \mathrm{me} 3$, which marks the 3 ' part $[52,65,66]$. The H3K79me2/H3K36me3 boundary corresponds to the first internal exon [52]. In animals, both H3K79me2 and H3K36me3 are considered to be associated with active transcription [65-67], and more specifically transcript elongation, although conflicting evidence has been reported [51]. In addition, a role has been proposed for $\mathrm{H} 3 \mathrm{~K} 79 \mathrm{me} 2$ in the regulation of alternative splicing [68], although again there is evidence to the contrary [52]. In fungi H3K79me2 has also been found to be associated with euchromatin and to be excluded from heterochromatin [69]. H3K79 methylation has not been detected in land plants [21]. Based on the different distribution patterns, H3K79me2 would appear to have different roles in animals and in brown algae.

We also observed that a region of chromosome six, containing a large, inserted DNA virus genome, was extensively marked with both H3K79me2 and H4K20me3. The viral genes at this locus have been shown to be transcriptionally silent in a range of tissues and life cycle stages [18], suggesting possible roles for H3K79me2 and H4K20me3 in defending the alga against lysogenic viral infections by silencing inserted viral genomes.

\section{Histone PTM patterns during the Ectocarpus life cycle}

To our knowledge this is the first study to have compared patterns of histone PTMs across the two generations of a haploid-diploid life cycle (although previous studies have looked at PTMs associated with the repression of germline genes during the sporophyte generation; [70,71]). Overall, genome-wide patterns of histone PTM were found to be stable between the Ectocarpus sporophyte and gametophyte generations, with the marks deposited at most genes remaining unchanged. The Ectocarpus sporophyte and gametophyte are very similar morphologically (near-isomorphy) and it is possible that more marked changes in histone PTM patterns occur during the life cycles of brown algal species (such as kelps) that exhibit greater differences between the sporophyte and gametophyte generations. However, note that there does not appear to be a strong correlation between the degree of morphological heteromorphy between life cycle generations and the proportion of GBGs in the genome [72]. Analysis of the epigenetic status of GBGs during the life cycle indicated that the differential expression patterns of these genes were correlated with modifications of multiple TSS-localised histone PTMs. Again, as stated 
above, is not clear at present whether these histone PTM modifications are involved in facilitating or potentiating gene upregulation or whether, on the contrary, changes in the transcription status of these genes leads to changes in the pattern of histone PTMs at the TSS.

\section{Conclusion}

513 This study provides a first overview of the nature and functions of histone PTMs in the brown

514 algae, a group that has evolved complex multicellularity independently of the animal and land

515 plant lineages. The general, emerging picture is that epigenetic regulatory mechanisms are

516 broadly conserved with those of other eukaryotic supergroups with some key differences that

517 will potentially provide important insights into the epigenetic regulation of developmental

518 processes, including novel histone modifications, unusual patterns of deposition of known

519 PTMs such as H3K79me2 and the absence of polycomb complexes. The data and resources

520 generated by this study will provide a foundation for future studies aimed at understanding

521 epigenetic processes in the brown algae.

\section{Material and Methods}

\section{Strains and growth conditions}

527 The Ectocarpus sp. strain used in this study was Ec32 [73]. Ectocarpus was cultivated as 528 described previously [74]. Cultures were grown at $13^{\circ} \mathrm{C}$ with a $12 \mathrm{~h} / 12 \mathrm{~h}$ day/night cycle and 20 $529 \mu \mathrm{mol}$ photons. $\mathrm{m}^{-2} \cdot \mathrm{s}^{-1}$ irradiance. Gametophytes were obtained from germinating meio-spores, 530 the sporophyte generation corresponded to partheno-sporophytes derived from parthenogenetic 531 gamete development.

\section{Detection of histone PTMs using mass spectrometry}

534 Ectocarpus histone proteins were isolated using the method described by Tirichine et al. [75]. 535 Briefly, histones were extracted from isolated nuclei in $1 \mathrm{M} \mathrm{CaCl}_{2}, 20 \mathrm{mM}$ Tris $\mathrm{HCl} \mathrm{pH} 7.4$ in 536 the presence of a cocktail of protease inhibitors. After precipitation of the acid-insoluble 537 fraction in $0.3 \mathrm{M} \mathrm{HCl}$, the histones were precipitated by dropwise addition of TCA, centrifuged and the pellet washed with $20 \%$ TCA and $0.2 \% \mathrm{HCl}$.

Gel purification and digestion of histones and mass spectrometry analysis were carried 540 out essentially as described by Veluchamy et al. [22]. Briefly, histone proteins, excised from a $541 \quad 14 \%$ SDS-polyacryamide gel, were digested overnight with endoproteinase $(12.5 \mathrm{ng} / \mu \mathrm{l})$, trypsin 
542 (Promega), chymotrypsin (12.5 ng/ $\mu 1$, Promega), ArgC (12.5 ng/ $\mu$ l, Promega) or elastase (20 $543 \mathrm{ng} / \mu \mathrm{l}$ Sigma-Aldrich). Peptides were analysed using a Q Exactive HF-X (Thermo Scientific) or 544 a TripleTOF ${ }^{\mathrm{TM}} 6600$ (ABSciex) mass spectrometer coupled to a RSLCnano system (Ultimate 3000, Thermo Scientific, Bremen, Germany). Spectra were generated using Xcalibur (version 2.0.7) and analysed with Mascot ${ }^{\mathrm{TM}}$ (version 1.4, Thermo Scientific) using an in-house database consisting of the complete Ectocarpus proteome available at Orcae [76]. The mass spectrometry proteomics data have been deposited in the PRIDE database [77] via ProteomeXchange with identifier PXD013535. Details of the liquid chromatography-tandem mass spectrometry parameters are provided in the Supplementary Methods.

\section{Detection of histone PTMs using immunoblots}

553 Commercially available antibodies (Additional file 5: Table S11) for a broad range of histone 554 PTMs were tested against Ectocarpus chromatin preparations using immunoblots as described 555 previously [78]. For antibodies that gave no signal or a weak signal with Ectocarpus extracts, 556 human HeLa cell extracts were used as a positive control. Briefly, HeLa cells were harvested and centrifuged at room temperature at $1500 \mathrm{rpm}$ for $5 \mathrm{~min}$ and then lysed in ice for 20 minutes using lysis buffer A (5 mM PIPES pH8.0, $85 \mathrm{mM} \mathrm{KCl,} \mathrm{0.5 \%} \mathrm{IGEPAL}{ }^{\circledR}$ CA-630). This cell extract was used for the immunoblot. An anti-histone H4 antibody (Millipore 05-858) was used as a loading control.

\section{Genome-wide detection of histone PTMs}

563 The ChIP-seq experiments were carried out in two batches, the first for H3K4me3, H3K9ac, and H3K27ac, the second for H3K4me2, H3K14ac, H3K36me3, H4K20me3, H3K79me2 and H3K27me3. RNA-seq data (see below) was generated for both batches to ensure that the histone PTM and gene expression data were fully compatible. For ChIP-seq, Ectocarpus tissue was fixed for five minutes in seawater containing $1 \%$ formaldehyde and the formaldehyde eliminated by rapid filtering followed by incubation in PBS containing $400 \mathrm{mM}$ glycine. Nuclei were isolated by grinding in liquid nitrogen and in a Tenbroeck Potter in nuclei isolation buffer (0.1\% triton X-100, $125 \mathrm{mM}$ sorbitol, $20 \mathrm{mM}$ potassium citrate, $30 \mathrm{mM} \mathrm{MgCl2,} 5 \mathrm{mM}$ EDTA, $5 \mathrm{mM} \beta$-mercaptoethanol, $55 \mathrm{mM}$ HEPES at $\mathrm{pH} 7.5$ with cOmplete ULTRA protease inhibitors), filtering through Miracloth and then washing the precipitated nuclei in nuclei isolation buffer with, and then without, triton X-100. Chromatin was fragmented by sonicating

574 the purified nuclei in nuclei lysis buffer (10 mM EDTA, 1\% SDS, $50 \mathrm{mM}$ Tris- $\mathrm{HCl}$ at pH 8 575 with cOmplete ULTRA protease inhibitors) in a Covaris M220 Focused-ultrasonicator (duty 
$25 \%$, peak power 75 , cycles/burst 200 , duration $900 \mathrm{sec}$ at $\left.6^{\circ} \mathrm{C}\right)$. The chromatin was incubated with an anti-histone PTM antibody (Additional file 5: Table S11) overnight at $4{ }^{\circ} \mathrm{C}$ and the immunoprecipitation carried out using Dynabeads protein A and Dynabeads protein G. Following immunoprecipitation and washing, a reverse cross-linking step was carried out by incubating for at least six hours at $65^{\circ} \mathrm{C}$ in $200 \mathrm{mM} \mathrm{NaCl}$ and the samples were then digested with Proteinase K and RNAse A. Purified DNA was analysed on an Illumina HiSeq 4000 platform with a single-end sequencing primer over 50 cycles. At least 20 million reads were generated for each immunoprecipitation (Additional file 5: Table S12).

Nuclei were prepared for MNase digestion using the same procedure as that used for ChIP samples except that the isolation buffer did not contain EDTA. Each sample of nuclei was digested with 400 agarose gel units of MNase for $10 \mathrm{~min}$ at $37^{\circ} \mathrm{C}$ in MNase reaction buffer (5 $\mathrm{mM} \mathrm{CaCl}_{2}, 60 \mathrm{mM} \mathrm{KCl}, 0.5 \mathrm{mM}$ DTT, $15 \mathrm{mM} \mathrm{NaCl}, 125 \mathrm{mM}$ sorbitol, $50 \mathrm{mM}$ Tris- $\mathrm{HCl} \mathrm{pH}$ 7.5). Following lysis of the nuclei, reverse cross-linking and digestion with Proteinase $\mathrm{K}$ and RNAse A, 120-210 bp fragments were excised from a 2\% agarose gel and sequenced on a HiSeq 4000 platform (Additional file 5: Table S12).

The ChIP-seq and MNase digestion datasets have been deposited in the NCBI Gene Expression Omnibus database, along with the associated RNA-seq data, under the accession number GSE146369.

Quality control of the sequence data was carried out using FASTQC [79]. Poor quality sequence was removed and the high quality sequence was trimmed with Flexcat [80]. Illumina reads were mapped onto the Ectocarpus genome ([18]; available at Orcae; [76]) using Bowtie [81]. Peaks corresponding to regions enriched in PTMs were identified using the MACS2 (version 2.1.1) callpeak module (minimum FDR of 0.01) and refined with the MACS2 bdgpeakcall and bdgbroadcall modules [82]. Additional file 5: Table S13 summarises the correspondence between PTM peaks and genes across the Ectocarpus genome. Co-localised peaks corresponding to regions enriched in several PTMs were detected using MACS2 outputs in BedTools multiinter [83]. Overlaps of PTM peaks with other genomic features were analysed using BedTools intercept [83]. The analysis of association of H3K79me2 domain borders with TSSs and TESs was carried out in R, using the function gr.rand from the package gUtils to generate the random anchors. Heatmaps, average tag graphs and coverage tracks were plotted using EaSeq software [84], deepTools [85] or pyGenomeTracks (https://pypi.org/project/pyGenomeTracks/). Circos graphs were generated using Circos software [86]. These analyses were carried out for two biological replicates for each PTM during both the sporophyte and gametophyte generations of the life cycle. Pearson correlation 
610 analysis between replicates was performed with deepTools 3.2.0 [85]. Replicate samples were 611 strongly correlated (Pearson correlations of 0.87 to 0.99; Additional file 4: Figure S10).

612 Normalisation was carried out using the input chromatin data (Additional file 5: Table S12).

613 Genome-wide analyses (e.g. Fig. 2) used data from sporophytes unless stated otherwise.

614

615 Comparisons of sporophyte and gametophyte transcriptomes using RNA-seq

616 RNA for transcriptome analysis was extracted from the same duplicate sporophyte and 617 gametophyte cultures that were analysed for each of the two ChIP-seq experiments using the 618 Qiagen RNeasy plant mini kit with an on-column Deoxyribonuclease I treatment. RNA quality 619 and concentration was then analysed on a Qubit ${ }^{\circledR} 2.0$ Fluorometer using Qubit RNA BR assay 620 kit (Invitrogen, Life Technologies, Carlsbad, CA, USA). Between 49 and 107 million sequence 621 reads were generated for each sample on an Illumina HiSeq 4000 platform with a single-end 622 sequencing primer over 150 cycles (Additional file 5: Table S12). Quality trimming of raw 623 reads was carried out with Flexcat [80] and reads of less than 50 nucleotides after trimming 624 were removed. Tophat2 [87] was used to map reads to the Ectocarpus genome [18] and the 625 mapped sequencing data was processed with featureCounts [88] to obtain counts for sequencing 626 reads mapped to exons. Expression values were represented as TPM. Differential expression 627 was detected using the DESeq2 package (Bioconductor; [89]) using an adjusted $p$-value cut-off 628 of 0.05 and a minimal fold-change of 2 . The set of GBGs corresponded to genes that were 629 significantly differentially regulated between life cycle generation in both of the ChIP-seq 630 experiments.

631

632 Searches for histone and histone modifying enzyme encoding genes in Ectocarpus

633 Histone and histone modifier genes were detected in the Ectocarpus genome [18] using Blast 634 [90] and manually reannotated when necessary, using GenomeView for structural reannotation 635 [91]. 
Additional file 1: Supplementary methods

Additional file 2: Figure S1. Histone gene clusters in the Ectocarpus genome.

Additional file 3: Figure S2. Representative MS/MS spectra showing the identification of histone modifications.

Additional file 4: Figure S3. Immunoblots of histone PTMs. Figure S4. Genomic distribution of the histone PTMs H3K79me2 and H4K20me3.Figure S5. Boundaries of H3K79me2 regions are preferentially located near TSSs and TESs. Figure S6. Comparison of genes marked with H3K79me2 alone, H4K20me3 alone or both H3K79me2 and H4K20me3. Figure S7. H3K79me2, H4K20me3, H3K36me3, H3K4me2, H3K4me3, H3K9ac, H3K14ac and H3K27ac signals for a region of chromosome 6 spanning an inserted viral genome. Figure S8. Correlations of transcript abundances and histone PTM signals for divergently transcribed pairs of genes. Figure S9. The histone PTM H2AK119ub1 was not detected in Ectocarpus. Figure S10. Pearson correlation scores for comparisons of the genomic distributions of ChIP-seq signal peaks for duplicate assays of the eight histone PTMs during both the sporophyte and gametophyte generations.

Additional file 5: Table S1. Histone proteins in Ectocarpus. Table S4. H4K20me3 peaks associated with different transposon families. Table S5. Genes with significantly different transcript abundances during the gametophyte and sporophyte generations. Table S6. Identification of enriched functional categories in the proteins encoded by the generation-biased gene set. Table S7. The generation-biased gene set is enriched in secreted proteins. Table S8. Analysis of long non-coding RNA genes that were differentially expressed during the gametophyte and sporophyte generations. Table S9. IncRNA GBGs with an adjacent proteincoding GBG. Table S10. Presence and absence of polycomb complex proteins in animals, land 661 plants and stramenopiles. Table S11. Anti-histone-PTM antibodies used in this study. Table 662 S12. Sequence data generated by this study. Table S13. Presence or absence of histone PTMs 663 and RNA-seq TPMs for all Ectocarpus genes in the sporophyte and the gametophyte 664 generations.

665 Additional file 6: Table S2. Putative PTM writers and erasers in Ectocarpus sp.

666 Additional file 7: Table S3. Presence or absence of histone post-translational modifications in 667 seven species from diverse eukaryotic supergroups.

\section{Acknowledgments}


671 We thank the Institut Français de Bioinformatique and the Roscoff Analysis and Bioinformatics

672 for Marine Science platform ABiMS (http://abims.sb-roscoff.fr) for providing computing and

673 data storage resources and Houda Benhelli-Mokrani for providing us with HeLa cells.

674

\section{Funding}

676

677 This work was supported by the Centre National de la Recherche Scientifique, Sorbonne 678 University (including a $\mathrm{PhD}$ grant for SB), the Agence Nationale de la Recherche projects 679 Epicycle and Idealg (ANR-19-CE20-0028-01 and ANR-10-BTBR-04-01) and the European 680 Research Council (grant agreement 638240). DL acknowledges support from the Région Ile681 de-France and the Fondation pour la Recherche Médicale.

\section{Availability of data and materials}

684

All sequence data used in this manuscript (Additional file 5: Table S12) have been deposited in the NCBI Gene Expression Omnibus (https://www.ncbi.nlm.nih.gov/geo/) under the accession number GSE146369. The Ectocarpus genome assembly is available through Orcae (https://bioinformatics.psb.ugent.be/orcae/overview/EctsiV2). The mass spectrometry proteomics data is available in the PRIDE database under accession number PXD013535.

\section{Authors' contributions}

SB prepared histones for mass spectrometry analysis and developed the ChIP-seq protocol with

694 help from LT, SB carried out the ChIP-seq analysis, BL and DL carried out the mass 695 spectrometry analysis of histone PTMs and analysed the data from these experiments, YW, SB 696 and LT carried out the immunoblots, SB and JMC analysed the ChIP-seq data with input from 697 LT and SMC, DS carried out additional experimental work, SB and JMC wrote the manuscript 698 with input from the other authors. All authors read and approved the final manuscript.

\section{Ethics approval and consent to participate}




\section{Consent for publication}

Not applicable.

\section{Competing interests}

The authors declare that they have no competing interests.

\section{References} Regulate Gene Expression. Trends Genet. 2016;32:42-56.

2. Cock JM, Godfroy O, Macaisne N, Peters AF, Coelho SM. Evolution and regulation of complex life cycles: a brown algal perspective. Curr Opin Plant Biol. 2014;17:1-6.

3. Coelho SM, Godfroy O, Arun A, Le Corguillé G, Peters AF, Cock JM. OUROBOROS is a master regulator of the gametophyte to sporophyte life cycle transition in the brown alga Ectocarpus. Proc Natl Acad Sci USA. 2011;108:11518-23.

4. Cock JM, Coelho SM. Algal models in plant biology. J Exp Bot. 2011;62:2425-30.

5. Macaisne N, Liu F, Scornet D, Peters AF, Lipinska A, Perrineau M-M, et al. The Ectocarpus IMMEDIATE UPRIGHT gene encodes a member of a novel family of cysteinerich proteins with an unusual distribution across the eukaryotes. Development. 2017;144:40918.

6. Godfroy O, Uji T, Nagasato C, Lipinska AP, Scornet D, Peters AF, et al.

$728 \quad 2017 ; 29: 3102-22$.

7. Arun A, Coelho SM, Peters AF, Bourdareau S, Pérès L, Scornet D, et al. Convergent recruitment of TALE homeodomain life cycle regulators to direct sporophyte development in

731 land plants and brown algae. eLife. 2019;8:e43101.

732 8. Müller DG. Generationswechsel, Kernphasenwechsel und Sexualität der Braunalge

733 Ectocarpus siliculosus im Kulturversuch. Planta. 1967;75:39-54.

734 9. Bothwell JH, Marie D, Peters AF, Cock JM, Coelho SM. Role of endoreduplication and 735 apomeiosis during parthenogenetic reproduction in the model brown alga Ectocarpus. New 736 Phytol. 2010;188:111-21.

737 10. Ohad N, Margossian L, Hsu YC, Williams C, Repetti P, Fischer RL. A mutation that 738 allows endosperm development without fertilization. Proc Natl Acad Sci U A. 1996;93:531973924. 
11. Ohad N, Yadegari R, Margossian L, Hannon M, Michaeli D, Harada JJ, et al. Mutations in $F I E$, a WD polycomb group gene, allow endosperm development without fertilization. Plant Cell. 1999;11:407-16. independent seed development in Arabidopsis thaliana. Proc Natl Acad Sci U A. 1997;94:4223-8.

13. Köhler C, Hennig L, Bouveret R, Gheyselinck J, Grossniklaus U, Gruissem W. Arabidopsis MSI1 is a component of the MEA/FIE Polycomb group complex and required for seed development. EMBO J. 2003;22:4804-14.

14. Guitton AE, Page DR, Chambrier P, Lionnet C, Faure JE, Grossniklaus U, et al. Identification of new members of Fertilisation Independent Seed Polycomb Group pathway involved in the control of seed development in Arabidopsis thaliana. Development. 2004;131:2971-81. produces nonviable parthenogenetic embryos in Arabidopsis. Curr Biol. 2005;15:750-4. maintenance by the Polycomb protein FIE has been conserved during land plant evolution. Development. 2009; 136:2433-44.

17. Okano Y, Aono N, Hiwatashi Y, Murata T, Nishiyama T, Ishikawa T, et al. A polycomb repressive complex 2 gene regulates apogamy and gives evolutionary insights into early land plant evolution. Proc Natl Acad Sci U A. 2009;106:16321-6. improved large-scale assembly and establishment of a catalogue of noncoding loci for the genome of the model brown alga Ectocarpus. New Phytol. 2017;214:219-32. Phylogeny-Based Systematization of Arabidopsis Proteins with Histone H1 Globular

766 Domain. Plant Physiol. 2017;174:27-34.

767 20. Johnson L, Mollah S, Garcia BA, Muratore TL, Shabanowitz J, Hunt DF, et al. Mass 768 spectrometry analysis of Arabidopsis histone H3 reveals distinct combinations of post769 translational modifications. Nucleic Acids Res. 2004;32:6511-8. translational modification patterns in Arabidopsis thaliana. PLoS One. 2007;2:e1210. analysis of post-translational histone modifications in the marine diatom Phaeodactylum

774 tricornutum. Genome Biol. 2015;16:102. genome and the independent evolution of multicellularity in brown algae. Nature.

777 2010;465:617-21. 
24. Gschloess1 B, Guermeur Y, Cock J.M. HECTAR: a method to predict subcellular targeting in heterokonts. BMC Bioinf. 2008;9:393.

780 25. Mozgova I, Hennig L. The polycomb group protein regulatory network. Annu Rev Plant 781 Biol. 2015;66:269-96.

782 26. Schuettengruber B, Bourbon H-M, Di Croce L, Cavalli G. Genome Regulation by 783 Polycomb and Trithorax: 70 Years and Counting. Cell. 2017;171:34-57.

784 27. Philpott A, Krude T, Laskey RA. Nuclear chaperones. Semin Cell Dev Biol. 2000;11:778514.

786 28. Nishitsuji K, Arimoto A, Iwai K, Sudo Y, Hisata K, Fujie M, et al. A draft genome of the 787 brown alga, Cladosiphon okamuranus, S-strain: a platform for future studies of "mozuku" 788 biology. DNA Res. 2016;23:561-70. 29. Nishitsuji K, Arimoto A, Higa Y, Mekaru M, Kawamitsu M, Satoh N, et al. Draft genome of the brown alga, Nemacystus decipiens, Onna-1 strain: Fusion of genes involved in the sulfated fucan biosynthesis pathway. Sci Rep. 2019;9:4607.

30. Ye N, Zhang X, Miao M, Fan X, Zheng Y, Xu D, et al. Saccharina genomes provide novel insight into kelp biology. Nat Commun. 2015;6:6986. H3K27me3 natural variation selectively marks genes predicted to be important for

796 differentiation in unicellular algae. bioRxiv. 2019;2019.12.26.888800.

32. Waterborg JH. Evolution of histone H3: emergence of variants and conservation of posttranslational modification sites. Biochem Cell Biol. 2012;90:79-95. phylogeny-based nomenclature for histone variants. Epigenetics Chromatin. 2012;5:7. factors and chromatin proteins in parasitic protists and other eukaryotes. Int J Parasitol. 2008;38:1-31.

804 35. Shaver S, Casas-Mollano JA, Cerny RL, Cerutti H. Origin of the polycomb repressive 805 complex 2 and gene silencing by an $\mathrm{E}(\mathrm{z})$ homolog in the unicellular alga Chlamydomonas. 806 Epigenetics. 2010;5:301-12.

807 36. Barnes CE, English DM, Cowley SM. Acetylation \& Co: an expanding repertoire of 808 histone acylations regulates chromatin and transcription. Essays Biochem. 2019;63:97-107.

809 37. Santos-Rosa H, Schneider R, Bannister AJ, Sherriff J, Bernstein BE, Emre NCT, et al. 810 Active genes are tri-methylated at K4 of histone H3. Nature. 2002;419:407-11.

811 38. Guenther MG, Levine SS, Boyer LA, Jaenisch R, Young RA. A chromatin landmark and 812 transcription initiation at most promoters in human cells. Cell. 2007;130:77-88. 
39. Akkers RC, van Heeringen SJ, Jacobi UG, Janssen-Megens EM, Françoijs K-J, Stunnenberg HG, et al. A hierarchy of H3K4me3 and H3K27me3 acquisition in spatial gene regulation in Xenopus embryos. Dev Cell. 2009;17:425-34.

40. Charron J-BF, He H, Elling AA, Deng XW. Dynamic landscapes of four histone modifications during deetiolation in Arabidopsis. Plant Cell. 2009;21:3732-48.

41. Karlić R, Chung H-R, Lasserre J, Vlahovicek K, Vingron M. Histone modification levels are predictive for gene expression. Proc Natl Acad Sci U S A. 2010;107:2926-31.

42. Dong X, Greven MC, Kundaje A, Djebali S, Brown JB, Cheng C, et al. Modeling gene expression using chromatin features in various cellular contexts. Genome Biol. 2012;13:R53.

43. Karmodiya K, Krebs AR, Oulad-Abdelghani M, Kimura H, Tora L. H3K9 and H3K14 acetylation co-occur at many gene regulatory elements, while $\mathrm{H} 3 \mathrm{~K} 14 \mathrm{ac}$ marks a subset of inactive inducible promoters in mouse embryonic stem cells. BMC Genomics. 2012;13:424.

44. Yang H, Howard M, Dean C. Antagonistic roles for H3K36me3 and H3K27me3 in the cold-induced epigenetic switch at Arabidopsis FLC. Curr Biol CB. 2014;24:1793-7.

45. Zhang F, Qi B, Wang L, Zhao B, Rode S, Riggan ND, et al. EIN2-dependent regulation of acetylation of histone H3K14 and non-canonical histone H3K23 in ethylene signalling. Nat Commun. 2016;7:13018.

46. Jurkowska RZ, Qin S, Kungulovski G, Tempel W, Liu Y, Bashtrykov P, et al. H3K14ac is linked to methylation of H3K9 by the triple Tudor domain of SETDB1. Nat Commun. 2017;8:2057.

47. Wu Z, Tang J, Zhuo J, Tian Y, Zhao F, Li Z, et al. Chromatin Signature and Transcription Factor Binding Provide a Predictive Basis for Understanding Plant Gene Expression. Plant Cell Physiol. 2019;60:1471-86.

48. Liu Y, Liu K, Yin L, Yu Y, Qi J, Shen W-H, et al. H3K4me2 functions as a repressive epigenetic mark in plants. Epigenetics Chromatin. 2019;12:40.

49. Zhang X, Bernatavichute YV, Cokus S, Pellegrini M, Jacobsen SE. Genome-wide analysis of mono-, di- and trimethylation of histone H3 lysine 4 in Arabidopsis thaliana. Genome Biol. 2009;10:R62.

50. Roudier F, Ahmed I, Bérard C, Sarazin A, Mary-Huard T, Cortijo S, et al. Integrative epigenomic mapping defines four main chromatin states in Arabidopsis. EMBO J. 2011;30:1928-38.

51. Barski A, Cuddapah S, Cui K, Roh T-Y, Schones DE, Wang Z, et al. High-resolution profiling of histone methylations in the human genome. Cell. 2007;129:823-37.

52. Huff JT, Plocik AM, Guthrie C, Yamamoto KR. Reciprocal intronic and exonic histone modification regions in humans. Nat Struct Mol Biol. 2010;17:1495-9.

53. Krogan NJ, Kim M, Tong A, Golshani A, Cagney G, Canadien V, et al. Methylation of Histone $\mathrm{H} 3$ by Set 2 in Saccharomyces cerevisiae Is Linked to Transcriptional Elongation by RNA Polymerase II. Mol Cell Biol. 2003;23:4207. 
54. Luco RF, Pan Q, Tominaga K, Blencowe BJ, Pereira-Smith OM, Misteli T. Regulation of alternative splicing by histone modifications. Science. 2010;327:996-1000.

55. Pajoro A, Severing E, Angenent GC, Immink RGH. Histone H3 lysine 36 methylation affects temperature-induced alternative splicing and flowering in plants. Genome Biol. 2017;18:102.

56. Mikkelsen TS, Ku M, Jaffe DB, Issac B, Lieberman E, Giannoukos G, et al. Genomewide maps of chromatin state in pluripotent and lineage-committed cells. Nature. 2007;448:553-60.

57. Balakrishnan L, Milavetz B. Decoding the histone H4 lysine 20 methylation mark. Crit Rev Biochem Mol Biol. 2010;45:440-52.

58. Xu J, Kidder BL. H4K20me3 co-localizes with activating histone modifications at transcriptionally dynamic regions in embryonic stem cells. BMC Genomics. 2018;19:514.

59. de la Paz Sanchez M, Gutierrez C. Arabidopsis ORC1 is a PHD-containing H3K4me3 effector that regulates transcription. Proc Natl Acad Sci U S A. 2009;106:2065-70.

60. Allshire RC, Madhani HD. Ten principles of heterochromatin formation and function. Nat Rev Mol Cell Biol. 2018;19:229-44.

61. Peters AHFM, Kubicek S, Mechtler K, O’Sullivan RJ, Derijck AAHA, Perez-Burgos L, et al. Partitioning and plasticity of repressive histone methylation states in mammalian chromatin. Mol Cell. 2003;12:1577-89.

62. Rice JC, Briggs SD, Ueberheide B, Barber CM, Shabanowitz J, Hunt DF, et al. Histone methyltransferases direct different degrees of methylation to define distinct chromatin domains. Mol Cell. 2003;12:1591-8.

63. Jiamu Du, Zhong X, Bernatavichute YV, Stroud H, Feng S, Caro E, et al. Dual binding of chromomethylase domains to H3K9me2-containing nucleosomes directs DNA methylation in plants. Cell. 2012;151:167-80.

64. Tarver JE, Cormier A, Pinzón N, Taylor RS, Carré W, Strittmatter M, et al. microRNAs and the evolution of complex multicellularity: identification of a large, diverse complement of microRNAs in the brown alga Ectocarpus. Nucl Acids Res. 2015;43:6384-98.

65. Steger DJ, Lefterova MI, Ying L, Stonestrom AJ, Schupp M, Zhuo D, et al. DOT1L/KMT4 recruitment and H3K79 methylation are ubiquitously coupled with gene transcription in mammalian cells. Mol Cell Biol. 2008;28:2825-39.

66. Bu J, Chen A, Yan X, He F, Dong Y, Zhou Y, et al. SETD2-mediated crosstalk between H3K36me3 and H3K79me2 in MLL-rearranged leukemia. Leukemia. 2018;32:890-9.

67. Schübeler D, MacAlpine DM, Scalzo D, Wirbelauer C, Kooperberg C, van Leeuwen F, et al. The histone modification pattern of active genes revealed through genome-wide chromatin analysis of a higher eukaryote. Genes Dev. 2004;18:1263-71.

68. Li T, Liu Q, Garza N, Kornblau S, Jin VX. Integrative analysis reveals functional and regulatory roles of H3K79me2 in mediating alternative splicing. Genome Med. 2018;10:30. 
69. $\mathrm{Ng} \mathrm{HH}$, Ciccone DN, Morshead KB, Oettinger MA, Struhl K. Lysine-79 of histone H3 is hypomethylated at silenced loci in yeast and mammalian cells: A potential mechanism for position-effect variegation. Proc Natl Acad Sci. 2003;100:1820.

70. Hoffmann RD, Palmgren MG. Epigenetic repression of male gametophyte-specific genes in the Arabidopsis sporophyte. Mol Plant. 2013;6:1176-86.

71. Jung CH, O'Brien M, Singh MB, Bhalla PL. Epigenetic landscape of germline specific genes in the sporophyte cells of Arabidopsis thaliana. Front Plant Sci. 2015;6:328.

72. Lipinska AP, Serrano-Serrano ML, Cormier A, Peters AF, Kogame K, Cock JM, et al. Rapid turnover of life-cycle-related genes in the brown algae. Genome Biol. 2019;20:35.

73. Peters AF, Scornet D, Ratin M, Charrier B, Monnier A, Merrien Y, et al. Life-cyclegeneration-specific developmental processes are modified in the immediate upright mutant of the brown alga Ectocarpus siliculosus. Development. 2008;135:1503-12.

74. Coelho SM, Scornet D, Rousvoal S, Peters NT, Dartevelle L, Peters AF, et al. How to cultivate Ectocarpus. Cold Spring Harb Protoc. 2012;2012:258-61.

75. Tirichine L, Lin X, Thomas Y, Lombard B, Loew D, Bowler C. Histone extraction protocol from the two model diatoms Phaeodactylum tricornutum and Thalassiosira pseudonana. Mar Genomics. 2014;13:21-5.

76. Sterck L, Billiau K, Abeel T, Rouzé P, Van de Peer Y. ORCAE: online resource for community annotation of eukaryotes. Nat Methods. 2012;9:1041.

77. Perez-Riverol Y, Csordas A, Bai J, Bernal-Llinares M, Hewapathirana S, Kundu DJ, et al. The PRIDE database and related tools and resources in 2019: improving support for quantification data. Nucleic Acids Res. 2019;47:D442-50.

78. Lin X, Tirichine L, Bowler C. Protocol: Chromatin immunoprecipitation (ChIP) methodology to investigate histone modifications in two model diatom species. Plant Methods. 2012;8:48.

79. Andrews S. FastQC A Quality Control tool for High Throughput Sequence Data. http://www.bioinformatics.babraham.ac.uk/projects/fastqc/. 2016.

80. Hansen P, Hecht J, Ibn-Salem J, Menkuec BS, Roskosch S, Truss M, et al. Q-nexus: a comprehensive and efficient analysis pipeline designed for ChIP-nexus. BMC Genomics. 2016;17:873.

81. Langmead B, Trapnell C, Pop M, Salzberg SL. Ultrafast and memory-efficient alignment of short DNA sequences to the human genome. Genome Biol. 2009;10:R25.

82. Zhang Y, Liu T, Meyer CA, Eeckhoute J, Johnson DS, Bernstein BE, et al. Model-based analysis of ChIP-Seq (MACS). Genome Biol. 2008;9:R137.

83. Quinlan AR, Hall IM. BEDTools: a flexible suite of utilities for comparing genomic features. Bioinforma Oxf Engl. 2010;26:841-2. 
84. Lerdrup M, Johansen JV, Agrawal-Singh S, Hansen K. An interactive environment for agile analysis and visualization of ChIP-sequencing data. Nat Struct Mol Biol. 2016;23:34957.

85. Ramírez F, Ryan DP, Grüning B, Bhardwaj V, Kilpert F, Richter AS, et al. deepTools2: a next generation web server for deep-sequencing data analysis. Nucleic Acids Res. 2016;44:W160-165.

931 86. Krzywinski M, Schein J, Birol I, Connors J, Gascoyne R, Horsman D, et al. Circos: an 932 information aesthetic for comparative genomics. Genome Res. 2009;19:1639-45.

933 87. Kim D, Pertea G, Trapnell C, Pimentel H, Kelley R, Salzberg SL. TopHat2: accurate 934 alignment of transcriptomes in the presence of insertions, deletions and gene fusions. Genome 935 Biol. 2013;14:R36.

936 88. Liao Y, Smyth GK, Shi W. featureCounts: an efficient general purpose program for 937 assigning sequence reads to genomic features. Bioinforma Oxf Engl. 2014;30:923-30.

938 89. Love MI, Huber W, Anders S. Moderated estimation of fold change and dispersion for 939 RNA-seq data with DESeq2. Genome Biol. 2014;15:550.

940 90. Altschul SF, Madden TL, Schaffer AA, Zhang J, Zhang Z, Miller W, et al. Gapped 941 BLAST and PSI-BLAST: a new generation of protein database search programs. Nucleic 942 Acids Res. 1997;25:3389-402.

943 91. Abeel T, Van Parys T, Saeys Y, Galagan J, Van de Peer Y. GenomeView: a next944 generation genome browser. Nucleic Acids Res. 2012;40:e12. autotrophic stramenopiles (Ochrophyta): substantive underestimation of putative fossil ages. PLoS One. 2010;5:e12759. 


\section{$951 \quad$ Figures}

\section{H2A $\mathrm{Ac}_{\text {Ac Ac }}$ anonical}

ACHN-SGIGKGGRGKKSTTRSAKAGLQFPVGRVGRFLKRGKYASRVGAGAPVYLAAVLEYLTAEVLELAGNAARDNKKARIIPRHIQLAVRNDEELNKLLGEVTIASGGVLPNIHAVLLPKKTVKK-COO'

H2A. $Z_{\text {Ac }}$ Ac Ac Ac Ac Ac

ACNH-SGIGGKGGKGGKGGKAPTSKKAPQSRSSKAGLQFPVG IHRFLKSRVHSHQRVGATSAVYTAAILEYLTAEVLELAGNACKDLKVKRITPRHLQLAIRGDEELDTLIKATIAGGGVIPHIHKSLVNKTTKKRI-COO-

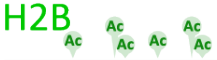

'H3N-AKTPSKKSAKAPKKAGDKKRTNKRTESYSSYYYKVLKQVVHPDTGISKRGMSIMNSFINDVFERVAGESGKLTRYNKKATLSSREVQTAVRLMLPGELAKHAVSEGTKAVTKFTSS-COO

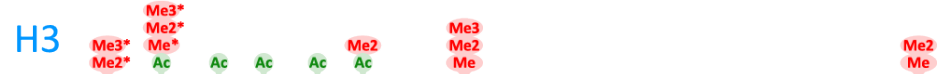

'H3N-ARTKQTARKSTGGKAPRKQLATKAARKSAPTAGGVKKPHRYRPGTVALREIRRYQKSTELLIRKLPFQRLVREIAQDFKTDLRFQSTAILALQEAAEAYLVGLFEDTNLCAIHAKRVTIMPKDIQLARRIRGERA-COO

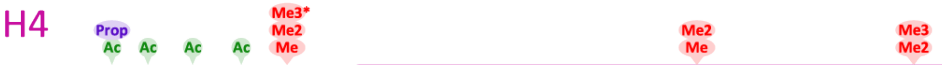

ACHN-SGRGKGGKGLGKGGAKRHRKVLRDNIQGITKPAIRRLARRGGVKRISGLIYEETRGVLKVFLENVIRDSVTYTEHARRKTVTAMDVVYALKRQGRTIYGFGG-COO-

b
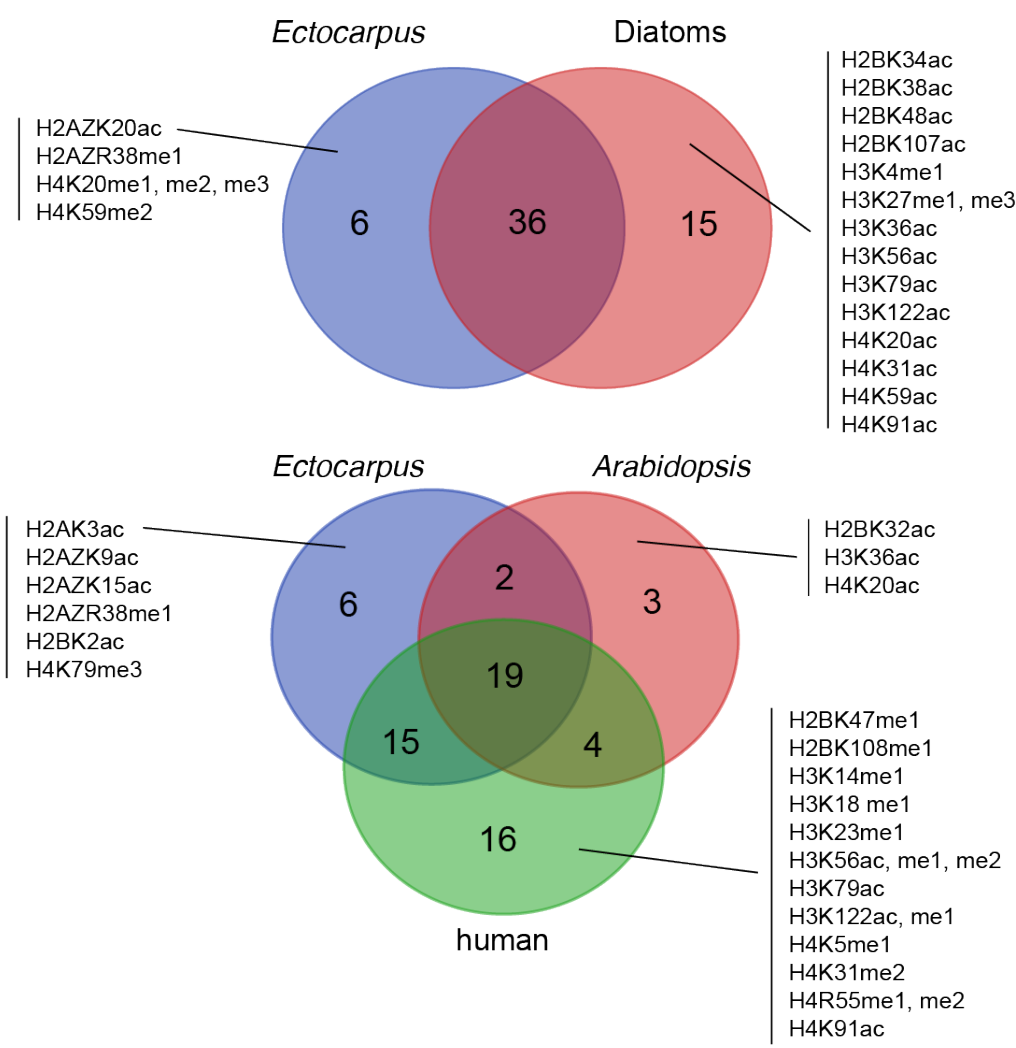

955 Fig. 1 a Post-translational modifications of Ectocarpus histones. Acetylation, methylation,

956 ubiquitylation and propionylation modifications of core and variant histones identified in this

957 study. Coloured boxes indicate globular core domains and grey boxes N- and C-terminal tails. 
958 Amino acid positions are indicated below the protein sequence. Asterisks indicate histone 959 modifications that were only detected using antibodies. All other modifications were detected 960 by mass spectrometry. b Comparison of the histone PTMs detected in Ectocarpus with PTMs 961 reported for diatoms (combined data for Phaeodactylum tricornutum and Thalassiosira 962 pseudonana, upper panel) and for humans and the land plant Arabidopsis (lower panel). See 963 Additional file 5: Table S3 for details. 
a

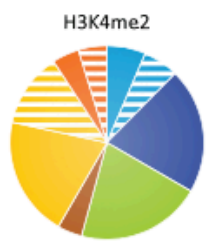

H3K27ac

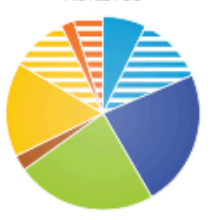

b

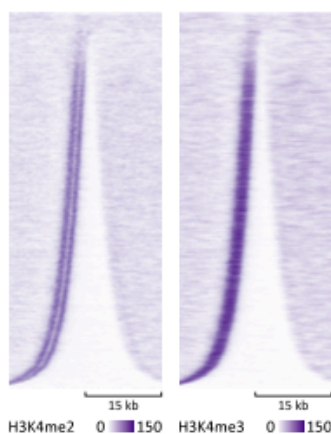

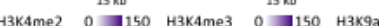

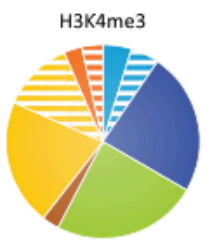

H3K36me3
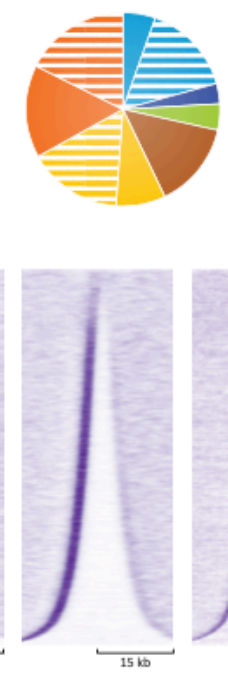

$15 \mathrm{~kb}$

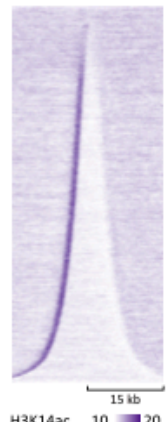

$15 \mathrm{~kb}$

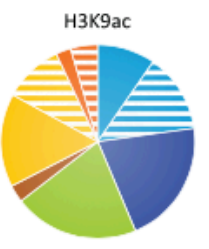

H3K79me2
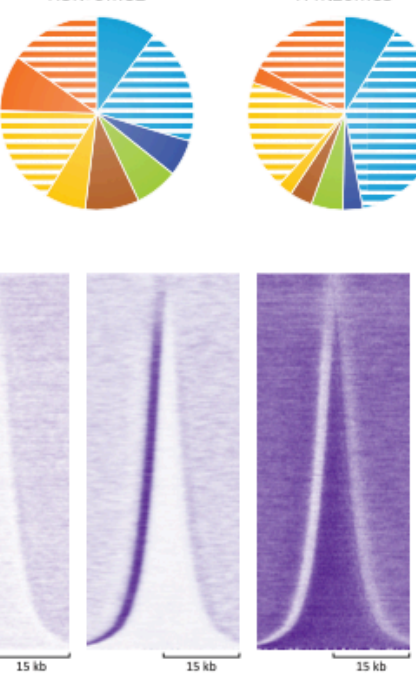

15 150
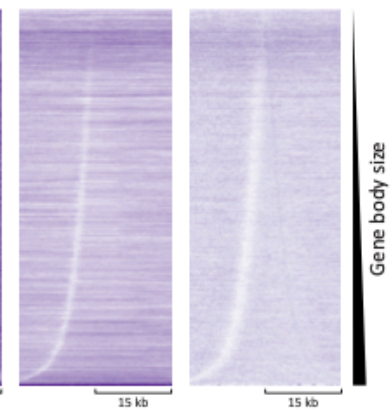

C

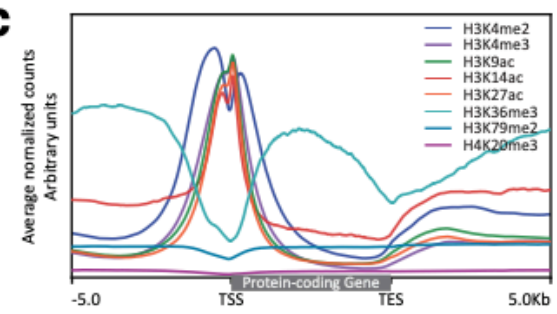

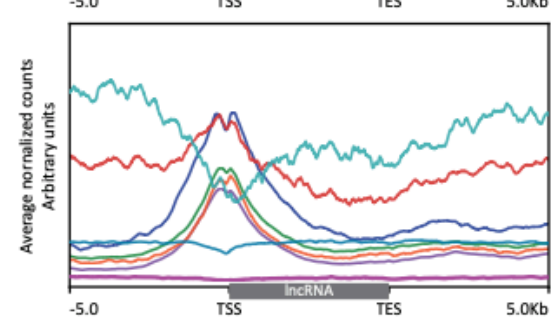

$\mathbf{e}$

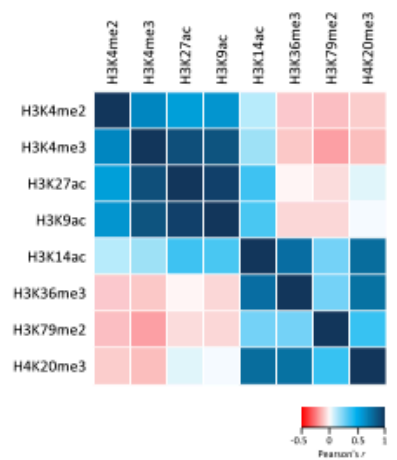

d

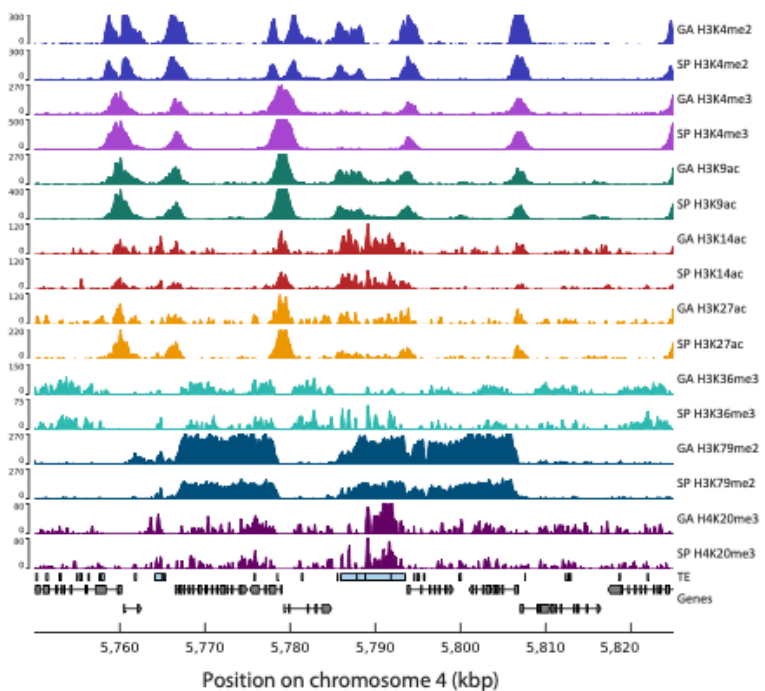

Fig. 2 Distribution of histone PTMs in the Ectocarpus genome. a Distribution of eight histone 
970 regions; Upstream TSS $500 \mathrm{bp}, 500 \mathrm{bp}$ region 5' to the transcription start site; Exon, all exon 971 sequence except first exons; Intron, all intron sequence except first introns. The sectors for 972 intergenic, intron and first intron regions have been separated in two to indicate values for 973 regions that contain TEs (white stripes) and regions that do not (full colour). b Distribution of 974 the eight histone PTMs across the complete set of Ectocarpus genes $(17,447)$ sorted by gene 975 body size and centred on the gene body. The black brackets correspond to 15 kilobases (kb). c 976 Enrichment profiles of the eight histone PTMs for all protein-coding (top panel) and all lncRNA 977 (bottom panel) genes. Gene bodies are plotted as proportional lengths, upstream and downstream intergenic regions in $\mathrm{kb}$. d Representative region of the chromosome 4 showing profiles of mapped ChIP-seq reads for the eight histone PTMs in the sporophyte (SP) and gametophyte (GA) generations. Light blue boxes represent transposons (TEs). Grey boxes and arrows represent exons superimposed on genes represented by a black line. e Pearson correlation scores for comparisons of the genomic distributions of ChIP-seq signal peaks for the eight histone PTMs. 

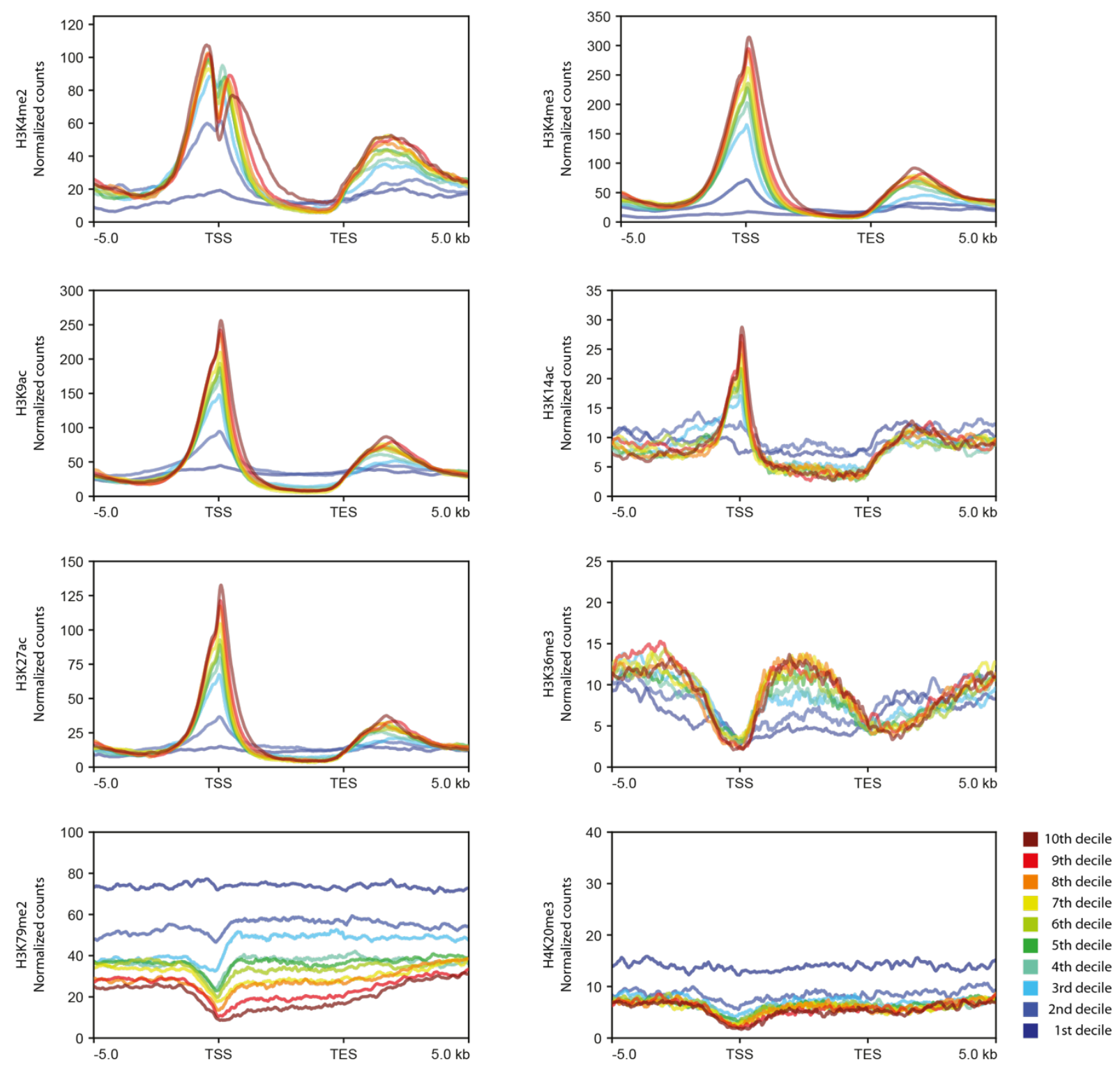

Fig. 3 Enrichment profiles for the histone PTMs H3K4me2, H3K4me3, H3K9ac, H3K14ac, H3K27ac, H3K36me3, H3K79me2 and H4K20me3 across genes expressed at different levels (TPM deciles). Gene bodies are plotted as proportional lengths, upstream and downstream intergenic regions in kilobases. TSS, transcription start site; TES, transcription end site, $\mathrm{kb}$, kilobases. 
a

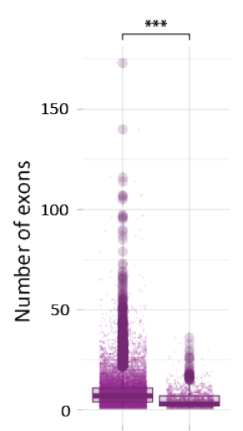

H4K20me3 no yes

d

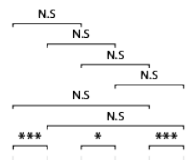

300

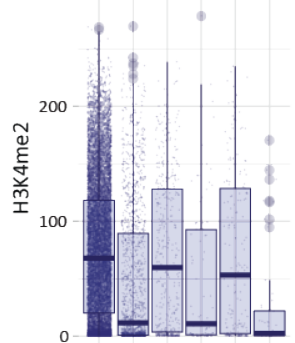

H4K20me3 no yes no yes no yes $\begin{array}{cc}\text { Un- } & \text { SP- } \\ \text { biased biased biased }\end{array}$ b
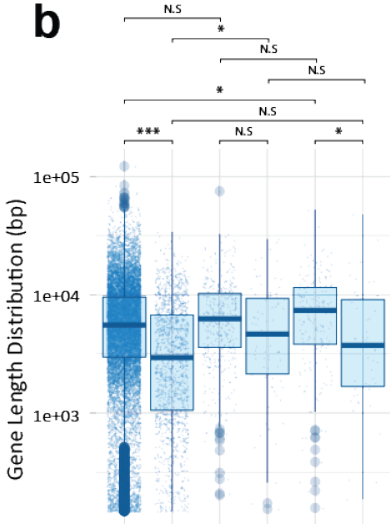

$\frac{\text { no yes }}{\text { Unbiased }} \frac{\text { no yes }}{\text { SP-biased }} \frac{\text { no yes }}{\text { GA-biased }}$
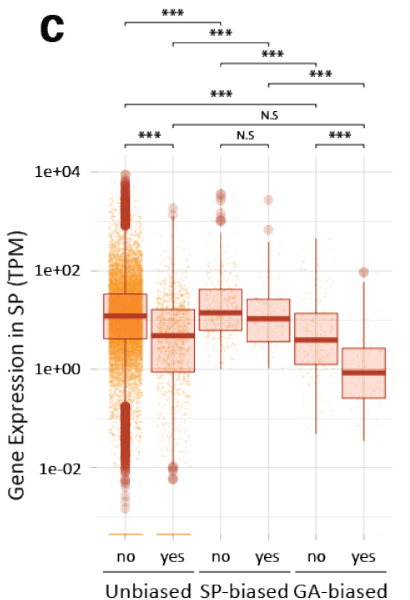

$\overline{\text { Unbiased }} \overline{\text { SP-biased GA-biased }}$

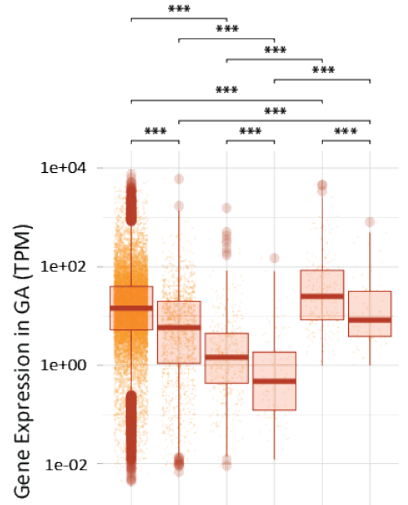

$\frac{\overline{\text { no }} \text { yes }}{\text { Unbiased }} \frac{\text { no yes }}{\text { SP-biased }} \frac{\text { no yes }}{\text { GA-biased }}$
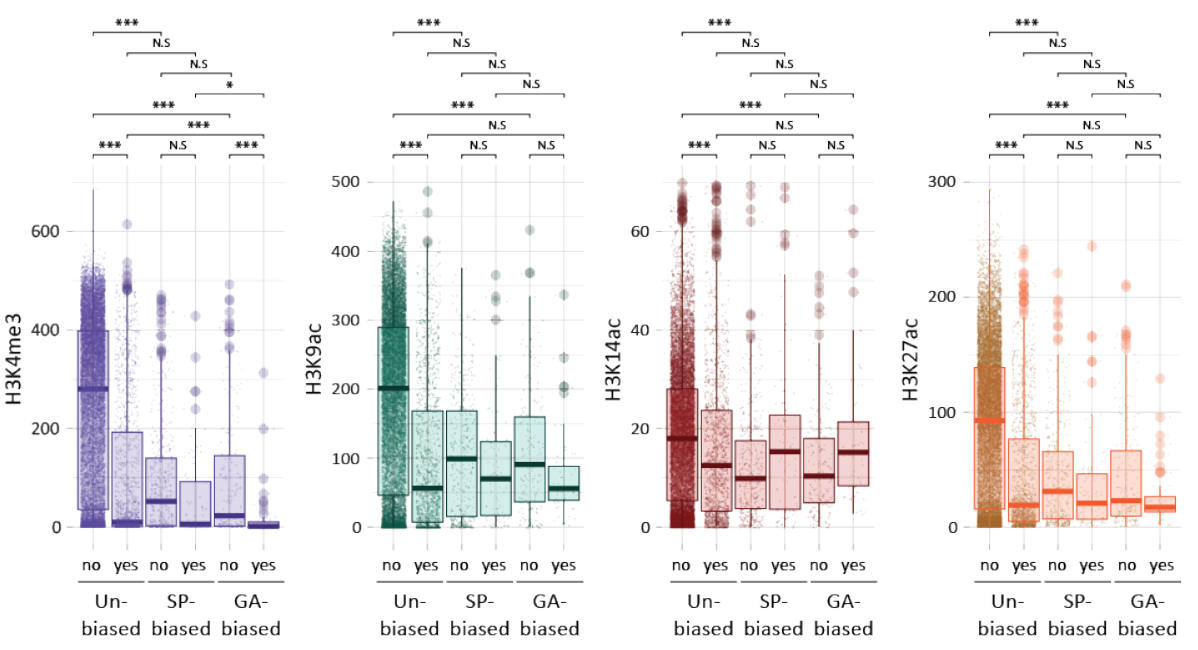

Fig. 4 Comparison of genes that contained or did not contain a H4K20me3 peak. a Genes with at least one H4K20me3 peak (yes) have fewer exons than genes without a H4K20me3 peak (no). b Lengths of genes with or without a H4K20me3 peak. c Abundances of transcripts for genes with or without a H4K20me3 peak. d Histone PTMs on genes with or without a H4K20me3 peak. SP, sporophyte; GA, gametophyte. Asterisks indicate significant differences (Bonferonni-adjusted Wilcoxon tests; ***, p $<0.0001$;, $\mathrm{p}<0.05$ ). 


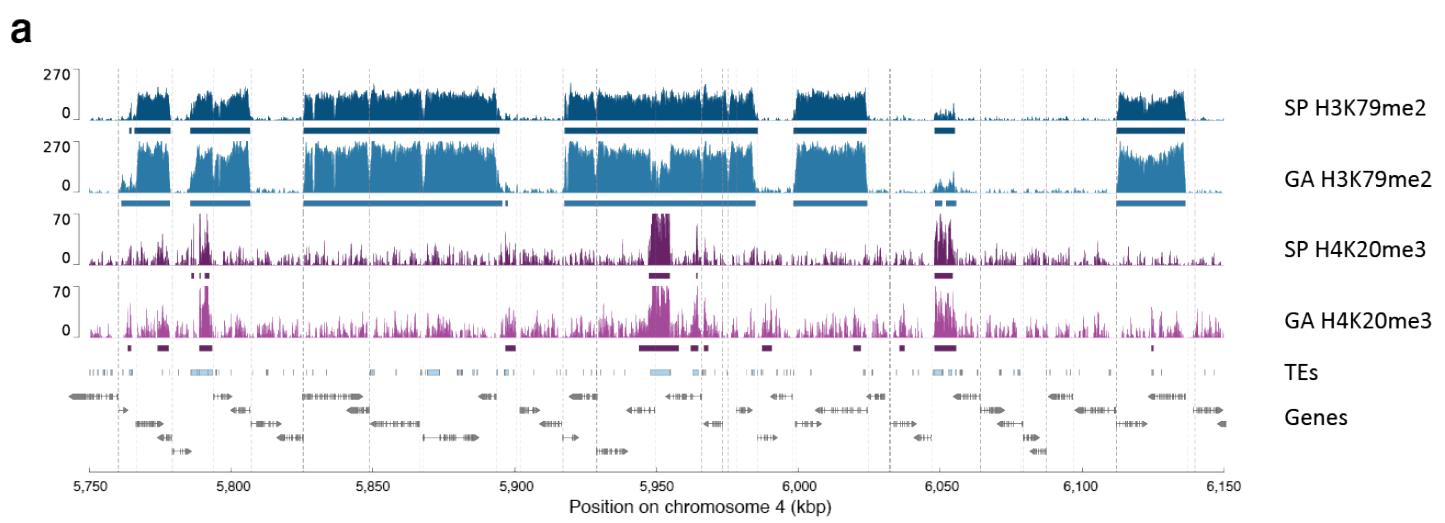

b
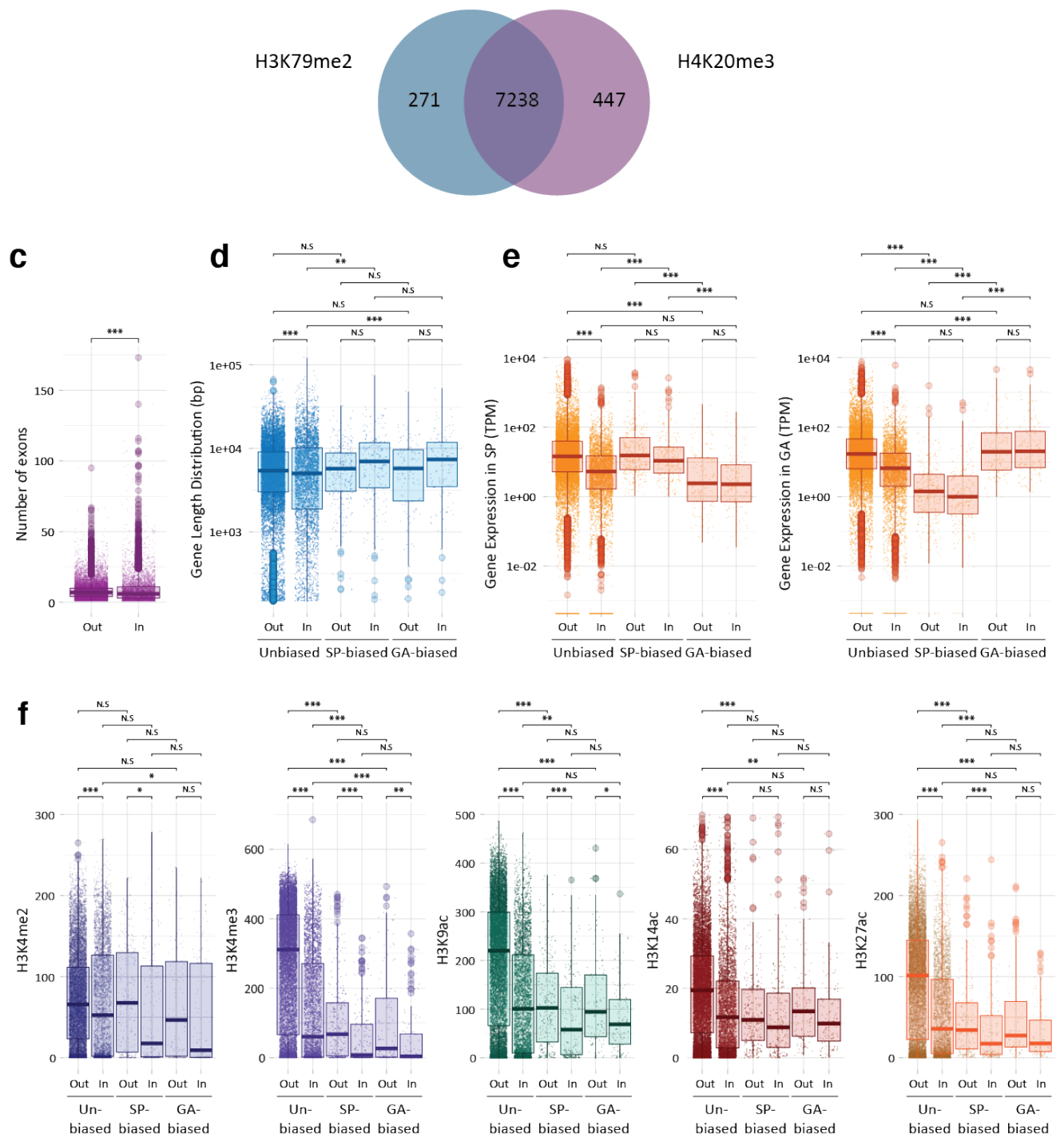

Fig. 5 Genomic distribution of the histone PTM H3K79me2. a Representative region of 0.4 Mbp from chromosome 4 (spanning the genes with LocusIDs Ec-04_005800 to Ec-04_006210) showing alternating regions marked or not with H3K79me2 (blue peaks) during both the sporophyte and gametophyte generations of the life cycle. Blue bars indicate H3K79me2 regions. The distribution of H4K20me3 (purple peaks) is also shown for comparison (peaks called by MACS2 are indicated by purple bars). Light blue boxes represent transposons (TEs). 
1016 Grey boxes and arrows represent exons superimposed on genes represented by a black line. 1017 Vertical dotted lines indicate the positions of TSSs. b Genome-wide overlap between peaks of 1018 H3K79me2 and H4K20me3. c Genes in H3K79me2 regions have fewer exons. d Lengths of 1019 genes within (In) or outside (Out) H3K79me2 regions. e Abundances of transcripts for genes within (In) or outside (Out) H3K79me 2 regions. f Histone PTMs on genes within (In) or outside (Out) H3K 79me 2 regions. A gene was considered to be "In" if more than $50 \%$ of the gene body (TSS-TES) was inside a H3K79me2 region. SP, sporophyte; GA, gametophyte; kb, kilobase pairs. Asterisks indicate significant differences (Bonferonni-adjusted Wilcoxon tests; $* * *, p<$ $0.0001 ; * *, \mathrm{p}<0.001 ; *, \mathrm{p}<0.05)$. 


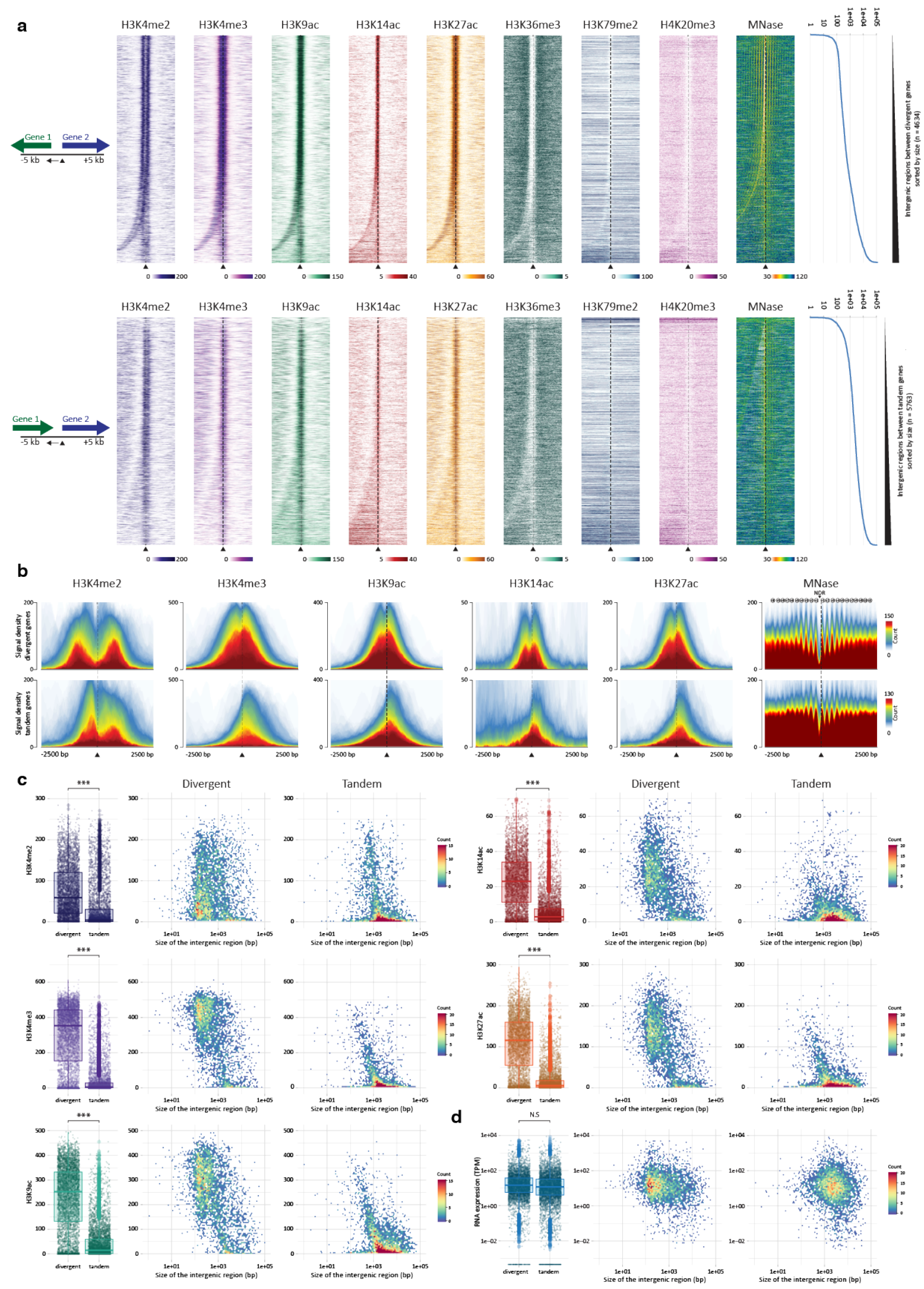


1028 Fig. 6 Histone PTM distributions in intergenic regions between divergent and tandemly organised pairs of genes. a Distribution of eight histone PTMs and MNase-sensitive sites in regions of $10 \mathrm{~kb}$ surrounding the TSS of the right-hand gene for pairs of either divergently (upper panel) or tandemly (lower panel) organised genes. The lengths of the intergenic regions are plotted on the right in bp. b Signal distributions for five TSS-localised histone PTMs and MNase-sensitive sites in regions of $5 \mathrm{~kb}$ surrounding the TSS of the right-hand gene for pairs of either divergently (upper plots) or tandemly (lower plots) organised genes on chromosome 4. c Abundance of five histone PTMs at the TSS of Gene 2 (see schema in A) in the intergenic regions of divergently or tandemly organised gene pairs together with plots indicating abundance in relation to the size of the intergenic region. $\mathbf{d}$ Transcript abundances for Gene 2 . For $\mathbf{c}$ and $\mathbf{d}$, heat score (count) indicates the number of genes with both the same PTM or transcript abundance and the same size intergenic region. MNase, micrococcal nuclease; $k b$, kilobases; bp, base pairs. 
a

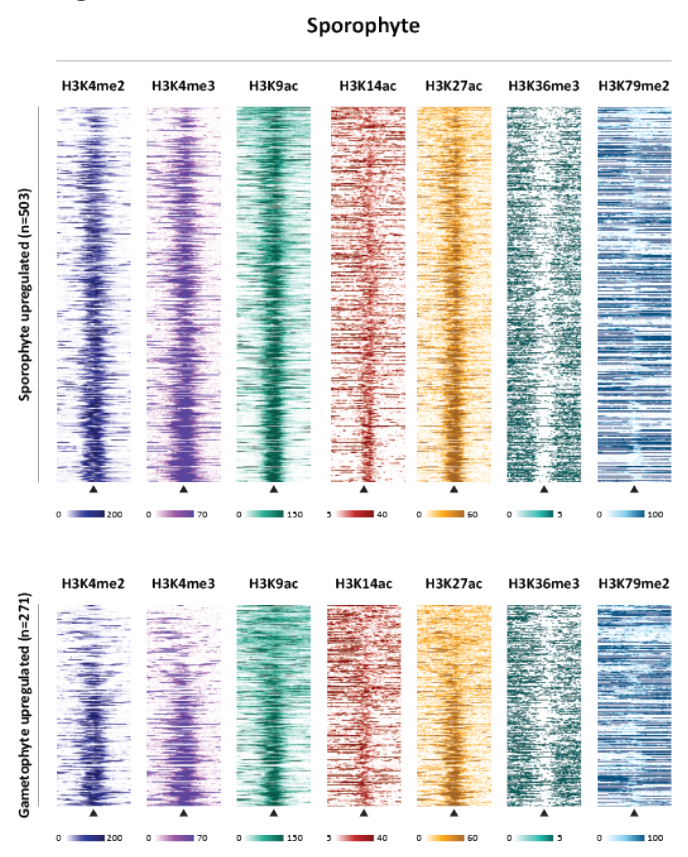

Gametophyte
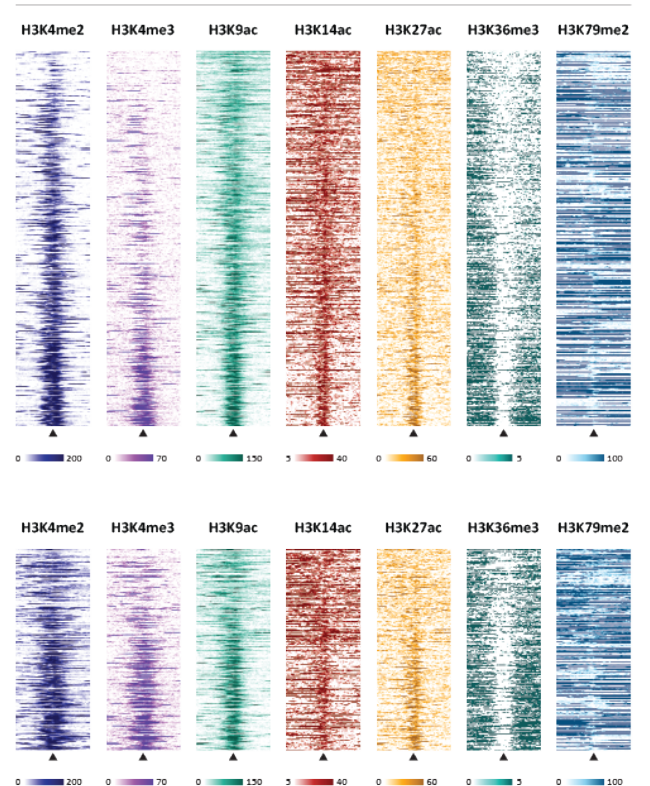

$\underbrace{\text { RNA }}_{\text {Ko tiss to to }} \begin{gathered}\text { Chromatin } \\ \text { (log2TPM) } \\ \text { states }\end{gathered}$

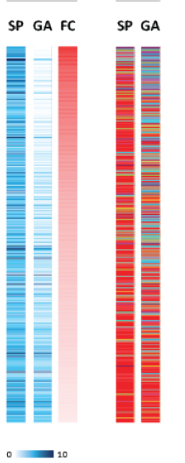

$:=$

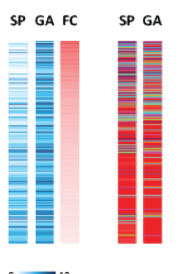

$:=$

b
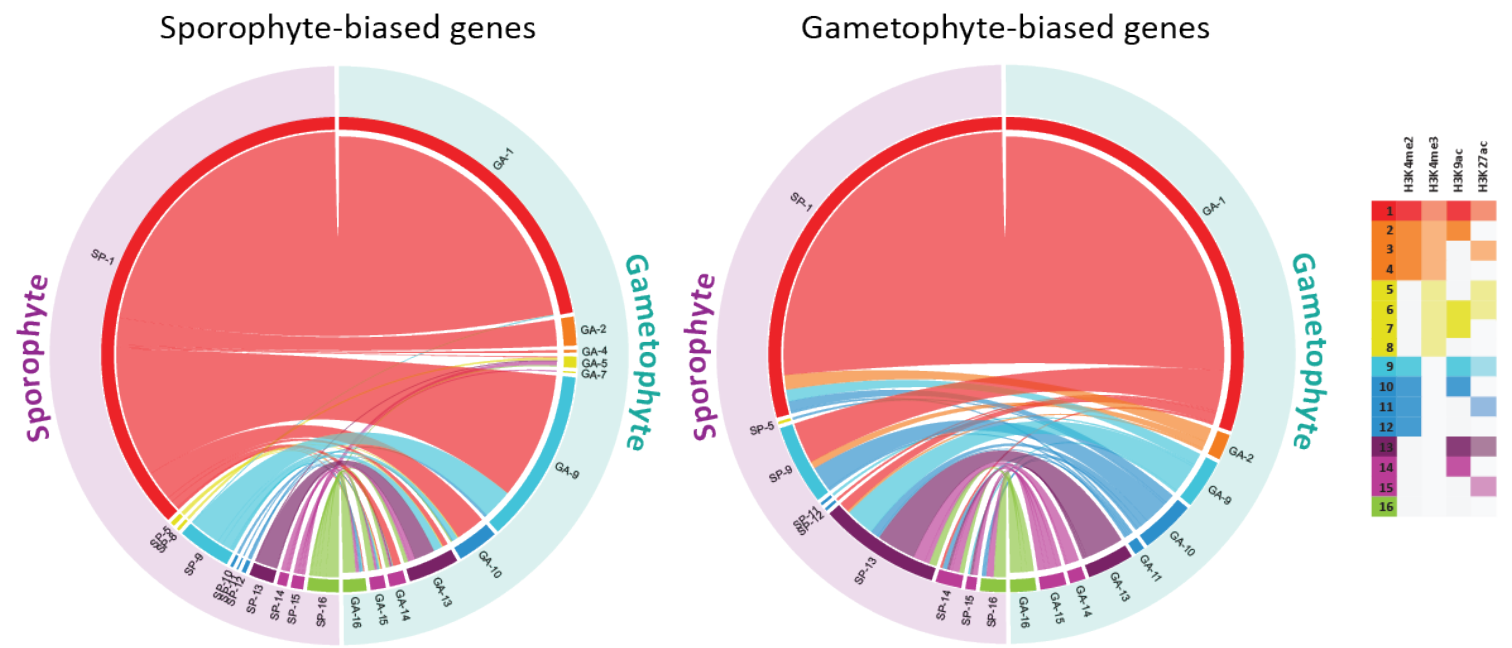

C
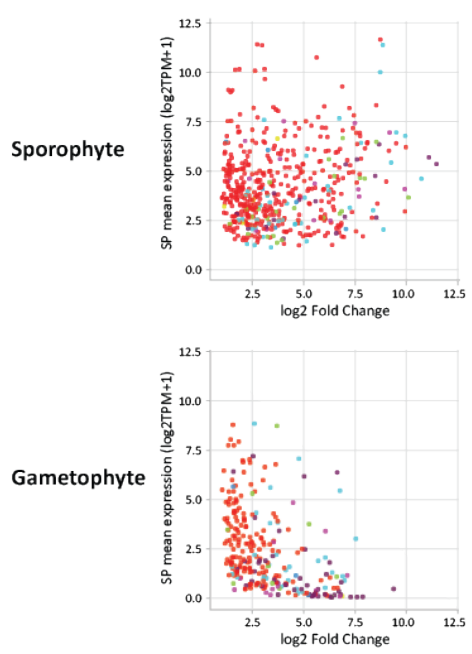
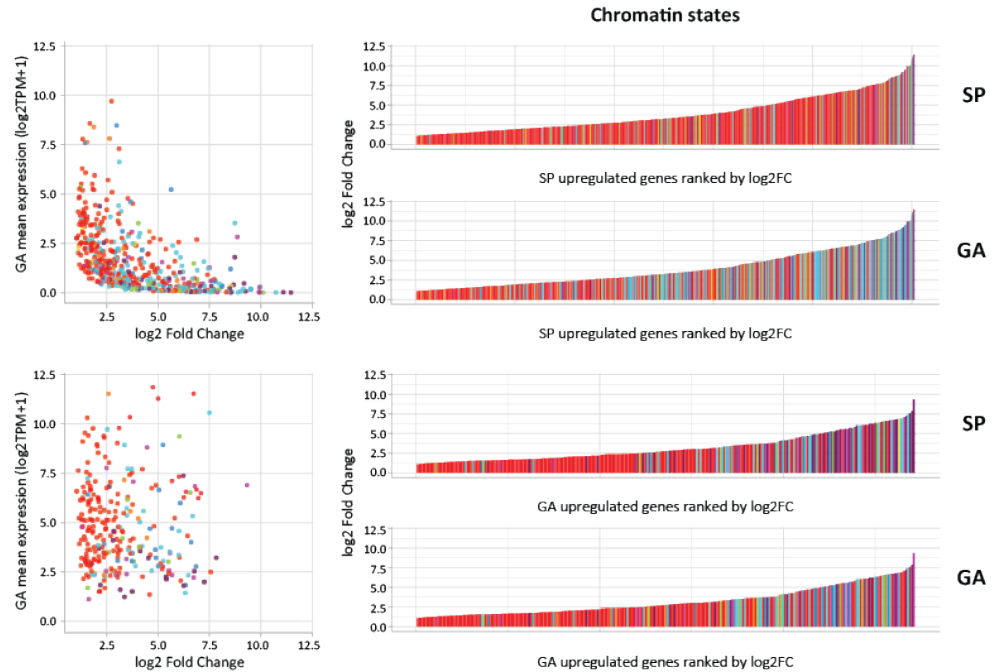
1044 Fig. 7 Alterations of histone PTM patterns at generation-biased genes during the two generations of the life cycle. a Patterns of histone PTMs over $10 \mathrm{~kb}$ regions surrounding the TSSs of sporophyte-biased (upper panel) and gametophyte-biased (lower panel) genes during the sporophyte (left) and gametophyte (middle) generations. The heatmaps on the right show transcript abundance during the two generations and $\log 2$ fold-change between generations. b Circos plots comparing chromatin states (combinations of histone PTMs) at the transcription start sites (TSS) of sporophyte-biased (left) and gametophyte-biased (left) genes in chromatin from the sporophyte (mauve) and gametophyte (green) generations of the life cycle. Colours correspond to chromatin states one to 16 as indicated in the key. $\mathbf{c}$ Plots of fold change against transcript abundance (TPM) for sporophyte- and gametophyte-biased genes during the two generations (left panel) along with ranked plots of fold change (right panel). Colour coding corresponds to chromatin states. 
a

PRC2

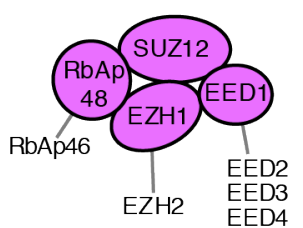

PRC1

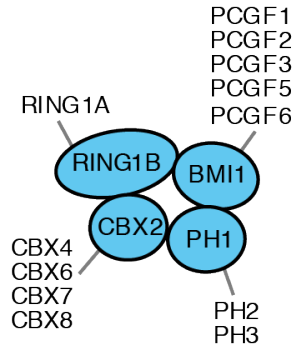

Arabidopsis
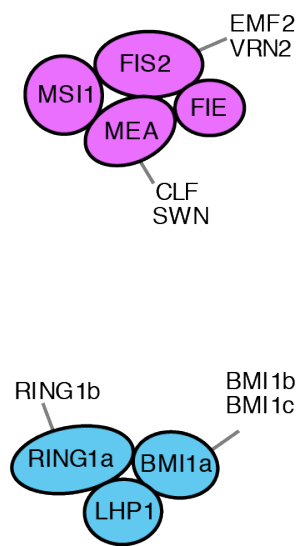

Phaeodactylum
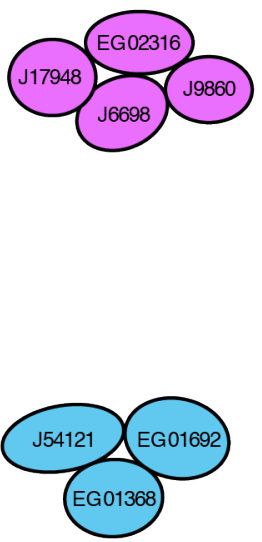

Ectocarpus
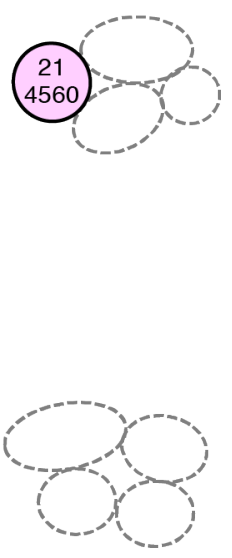

b

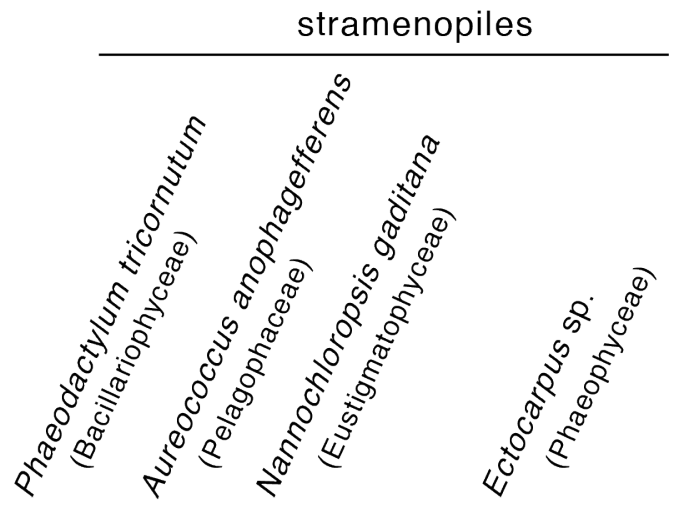

Fig. 8 Loss of polycomb complexes from brown algae. a Core components of the polycomb complexes PRC2 (mauve) and PRC1 (blue) in Homo sapiens, Arabidopsis thaliana, Phaeodactylum tricornutum and Ectocarpus sp.. Mauve or blue circles indicate the presence of a PRC2 or PRC1 gene, respectively. RbAp48 is indicated in pink when it probably represents a component of other cellular complexes (see text for details). Alternative proteins are shown 
1065 for each component. Empty, dotted circles indicate components that are absent from 1066 Ectocarpus. All P. tricornutum and Ectocarpus sp. protein names should be prefixed with 1067 Phatr3 or Ec-, respectively, e.g. Phatr3_J17948, Ec-21_004560. b Schematic phylogenetic tree 1068 indicating PRC2 and PRC1 genes present in Homo sapiens, Arabidopsis thaliana and four 1069 selected stramenopiles. Red bars indicate predicted approximate timepoints for loss of the 1070 PRC1 and PRC2 complexes during stramenopile evolution. Approximate divergence times $1071( \pm 100 \mathrm{My})$ are based on Brown and Sorhannus [92]. 


\section{Supplementary figures}

1076

1077

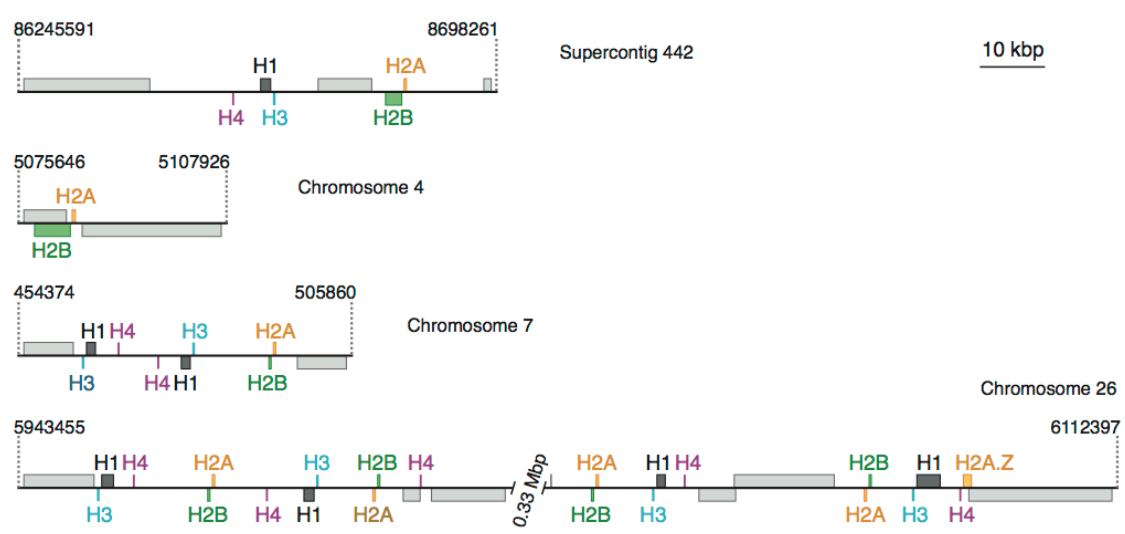

Fig. S1 Histone gene clusters in the Ectocarpus genome. Only regions with two or more histone genes are shown. Coding regions from the start to the stop codon are shown as boxes. Histone genes are colour coded, flanking, non-histone genes are in grey. Genes above the line are transcribed to the right, genes below the line to the left. Dotted lines indicate chromosomal or scaffold coordinates. 
(see additional file 3 for figure)

Fig. S2 Representative MS/MS spectra showing the identification of histone modifications. Trypsin-peptide-derived LC-ESI MS/MS fragmentation spectra for modified H2, H3 and H4 peptides. The inset shows the peptide sequence and the observed ions. Tandem mass spectra are labelled to show singly and/or doubly charged $\mathrm{b}$ and $\mathrm{y}$ ions, as well as ions corresponding to neutral loss of water $\left(^{\circ}\right)$ or $\mathrm{NH}_{3}(*)$. M is the parent ion mass and $\mathrm{Im}$ the immonium ion mass. Me, methylation; DiMe, dimethylation: TriMe, trimethylation, Prop, propionylation; Ac, Acetylation, Ub, ubiquitination; N-ter, N-terminal. 
1099
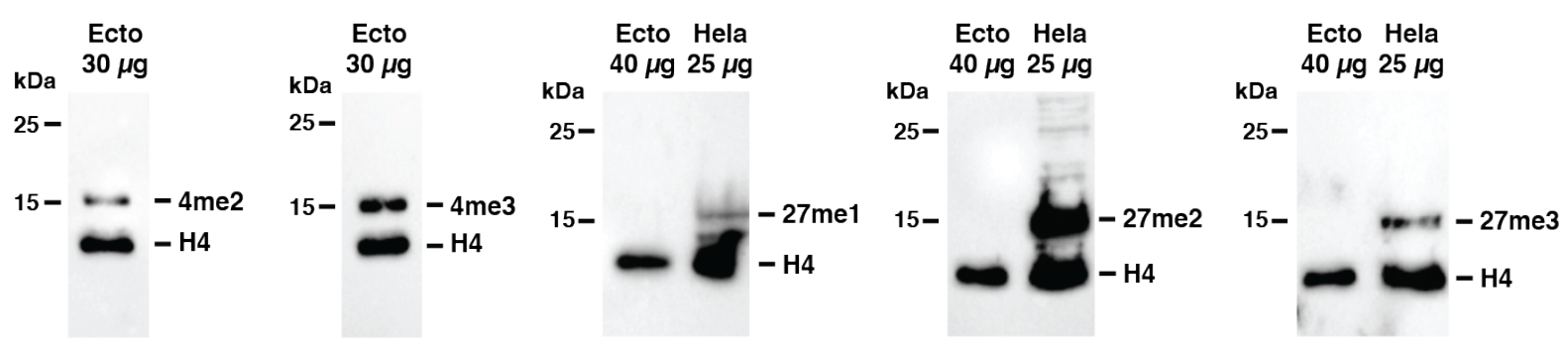

1100
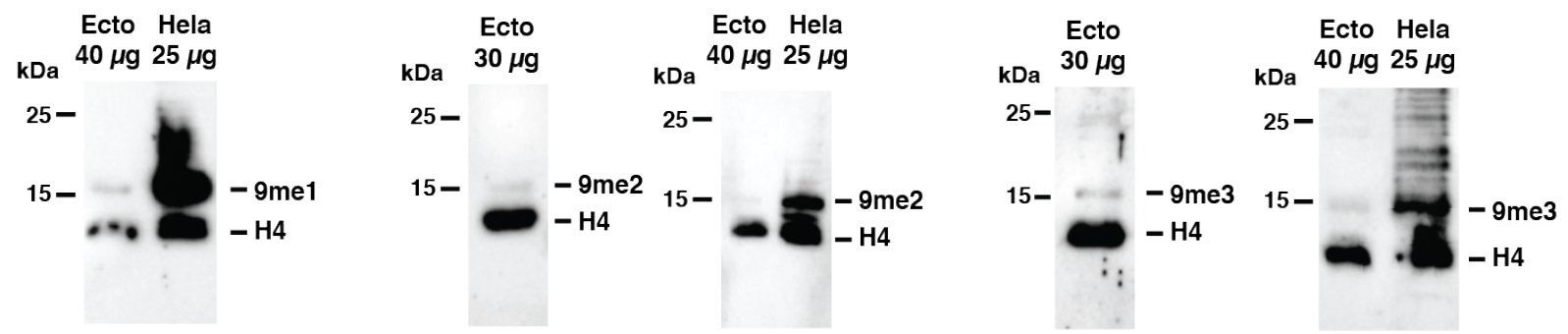

1101

1102

Fig. S3 Immunoblots of histone PTMs. Detection of histone PTMs H3K4me2 (4me2), H3K4me3 (4me3), H3K27me1 (27me1), H3K27me2 (27me2), H3K27me3 (27me3), H3K9me1 (9me1), H3K9me2 (9me2) and H3K9me3 (9me3) in either $30 \mu \mathrm{g}$ or $40 \mu \mathrm{g}$ of Ectocarpus chromatin extract (Ecto) or in $25 \mu \mathrm{g}$ of human HeLa cell chromatin extract (HeLa) as a positive control. Histone $\mathrm{H} 4$ (H4) was detected as a loading control. Note that a weak, but probably non-specific, signal was obtained for H3K27me3 in Ectocarpus extracts following long exposure times (10 min rather than the standard $50 \mathrm{sec}$ ). 

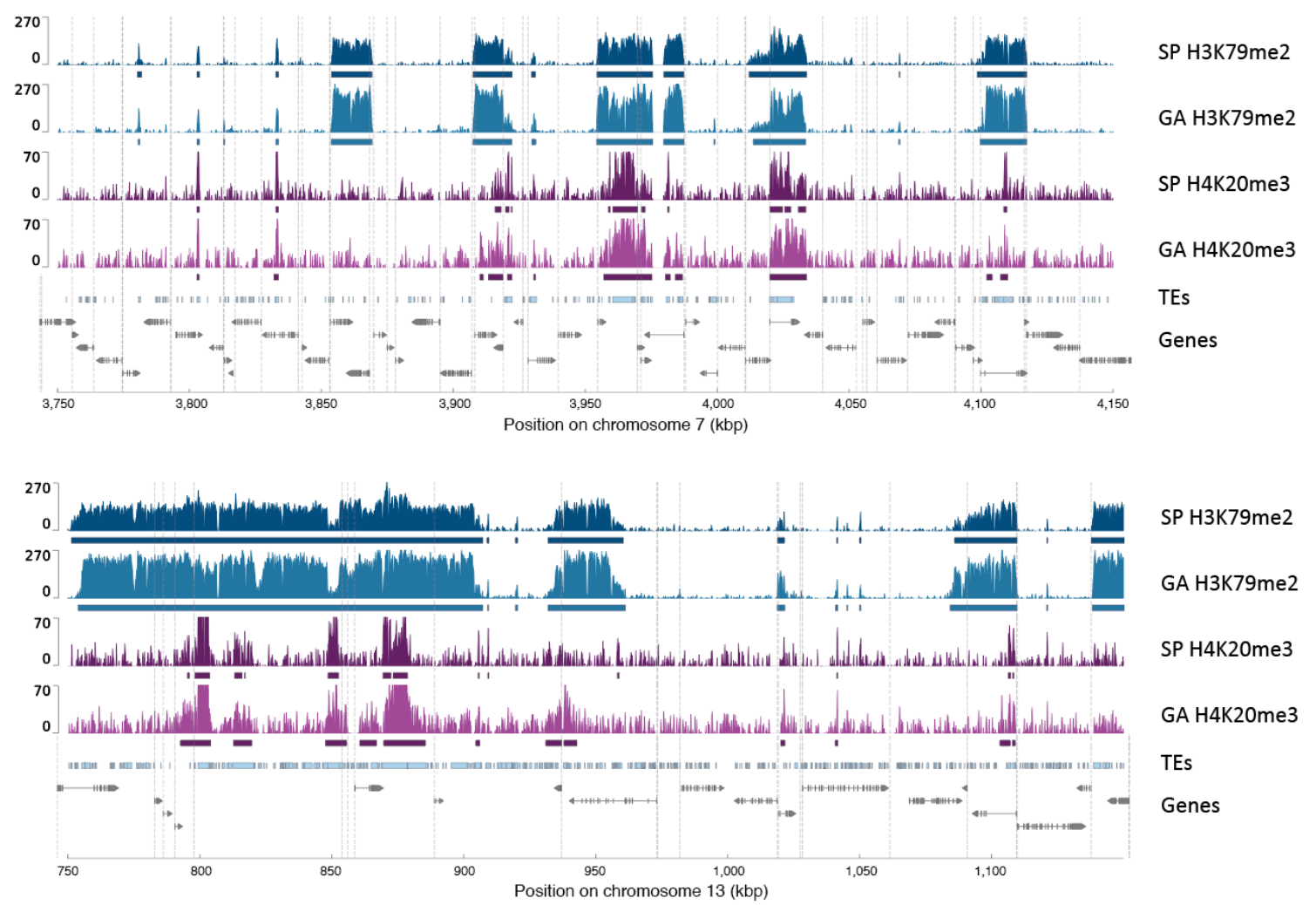

Fig. S4 Genomic distribution of the histone PTMs H3K79me2 and H4K20me3. Representative regions of chromosomes 7 and 13 (spanning the genes with LocusIDs Ec -07_003700 to Ec07_004180 and Ec-13_000140 to Ec-13_000350, respectively) showing alternating regions marked or not with $\mathrm{H} 3 \mathrm{~K} 79$ me2 (blue peaks) during both the sporophyte and gametophyte generations of the life cycle. Dark blue bars indicate H3K79me2 regions. The distribution of H4K20me3 (purple peaks) is also shown for comparison (peaks called by MACS2 are indicated by purple bars). Light blue boxes represent transposons (TEs). Grey boxes and arrows represent exons superimposed on genes represented by a black line. Vertical dotted lines indicate the positions of TSSs. 


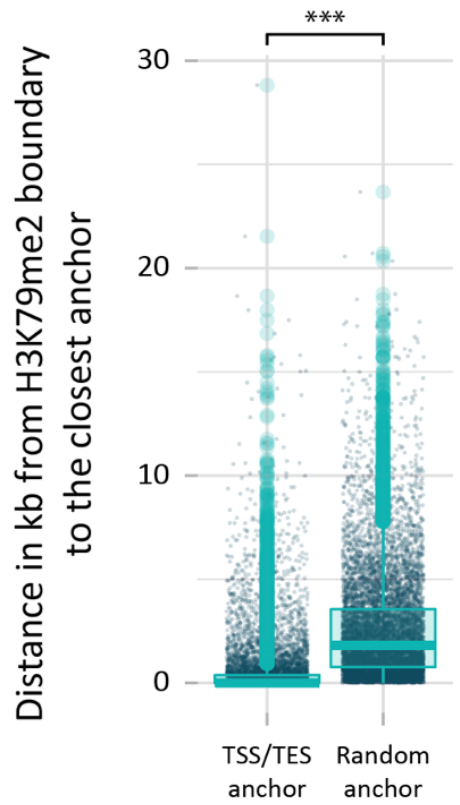

Fig. S5 Boundaries of H3K79me2 regions are preferentially located near TSSs and TESs. The 

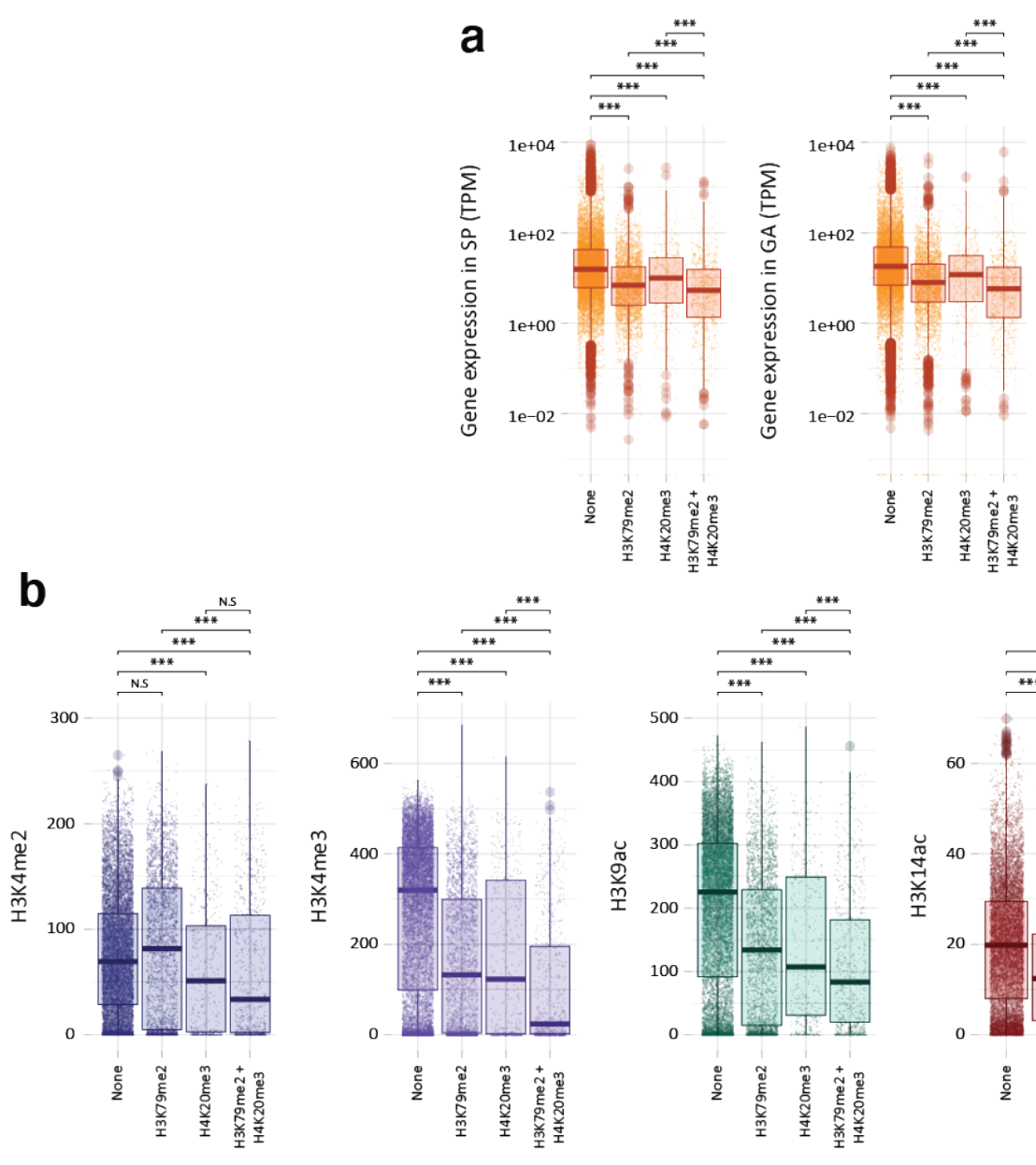

1132

1133

1134

1135

1136

1137

1138

1139

1140

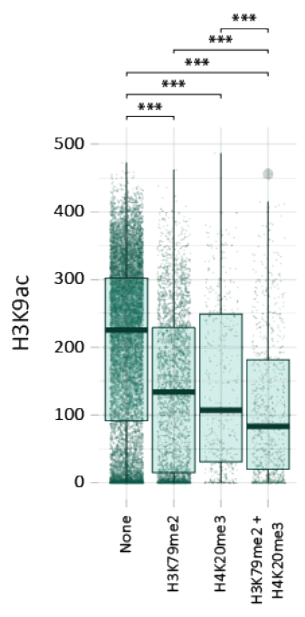

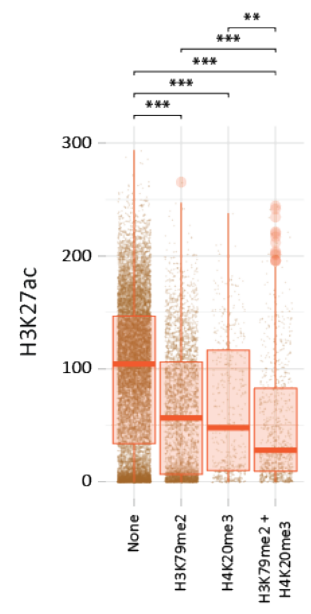

Fig. S6 Comparison of genes marked with H3K79me2 alone, H4K20me3 alone or both H3K79me2 and H4K20me3. a Abundances of transcripts for genes marked with H3K79me2 alone, H4K20me3 alone or both H3K79me2 and H4K20me3. b Histone PTMs on genes marked with H3K79me2 alone, H4K20me3 alone or both H3K79me2 and H4K20me3. SP, sporophyte; GA, gametophyte. Asterisks indicate significant differences (Bonferonni-adjusted Wilcoxon tests; $\left.{ }^{* * *}, \mathrm{p}<0.0001 ; * *, \mathrm{p}<0.001 ;^{*}, \mathrm{p}<0.05\right)$. 


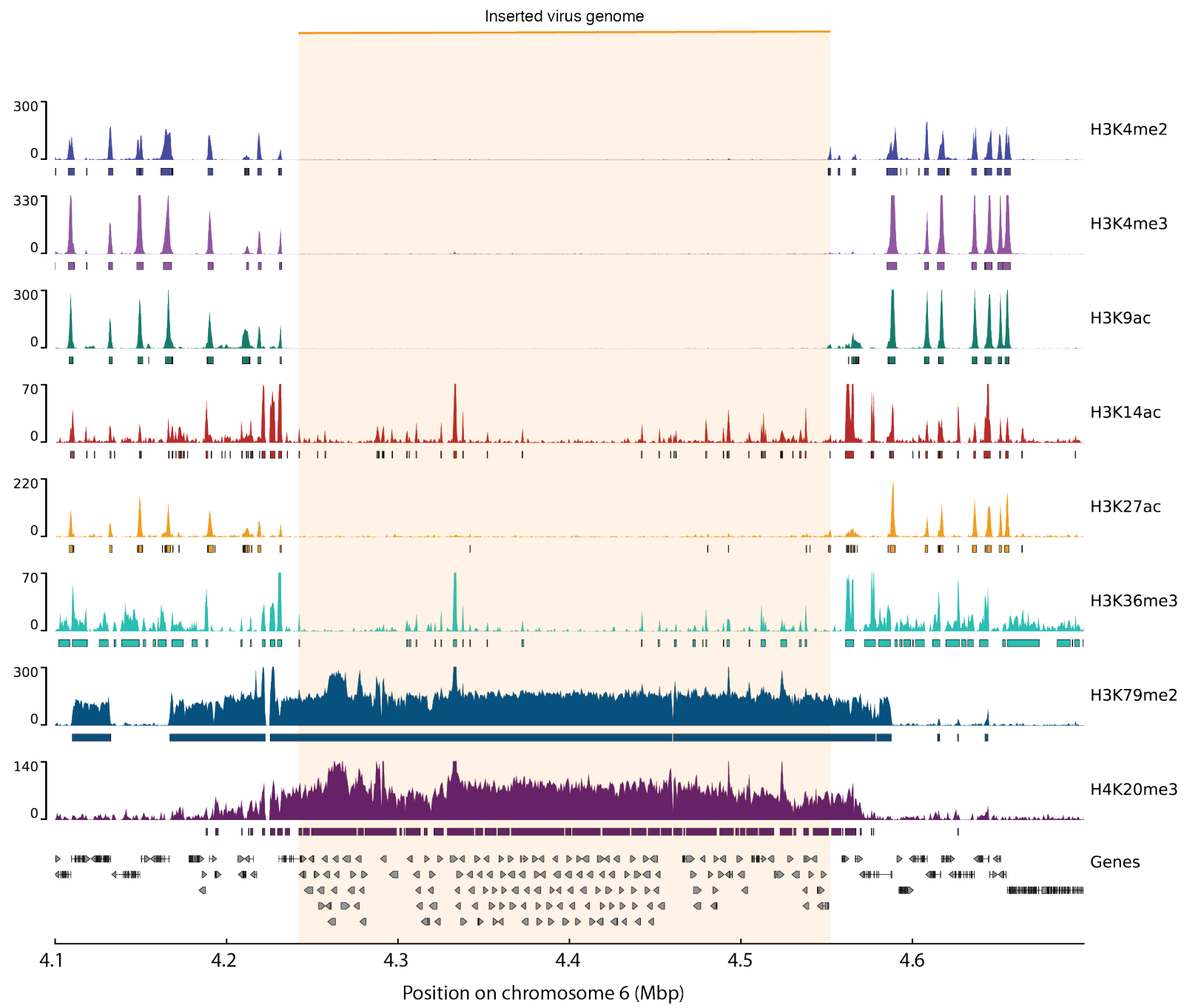

Fig. S7 H3K79me2, H4K20me3, H3K36me3, H3K4me2, H3K4me3, H3K9ac, H3K14ac and $\mathrm{H} 3 \mathrm{~K} 27 \mathrm{ac}$ signals for a region of chromosome 6 spanning an inserted viral genome (orange box). Coloured boxes indicate histone PTM peaks, grey boxes and arrows represent exons superimposed on genes represented by a black line. 

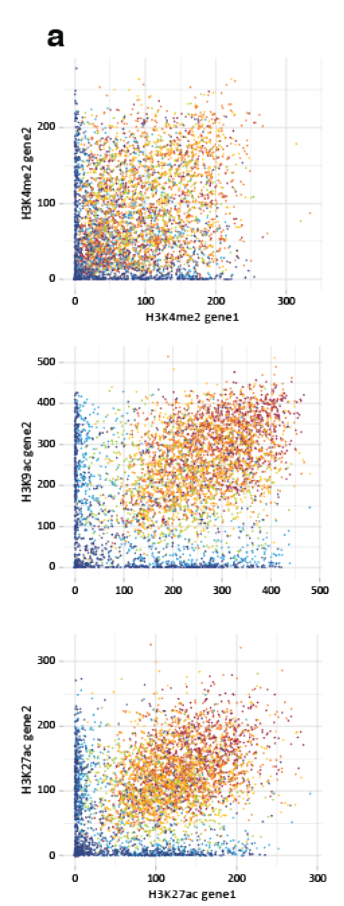
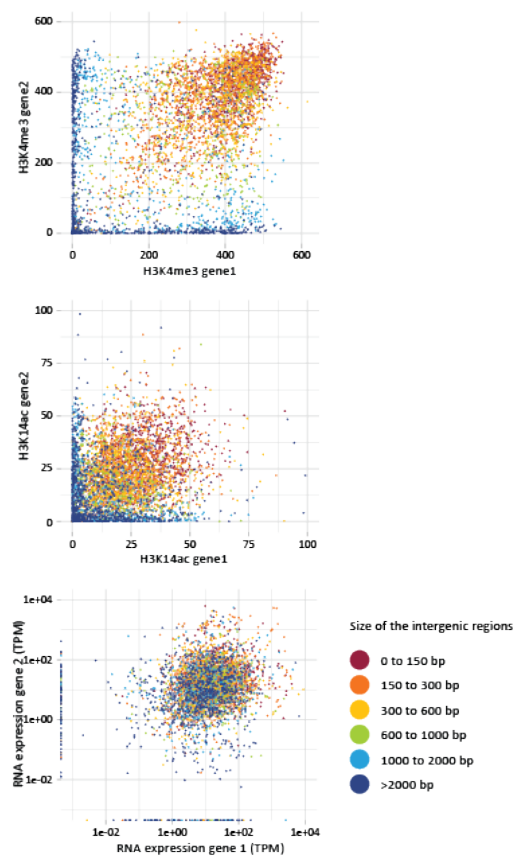

b
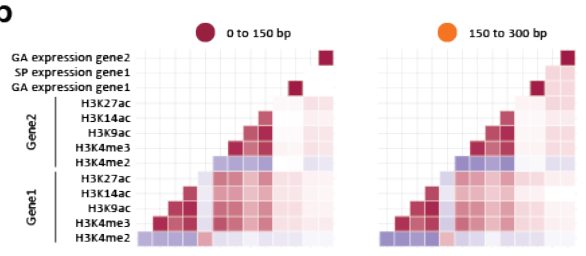

300 to 600 bp
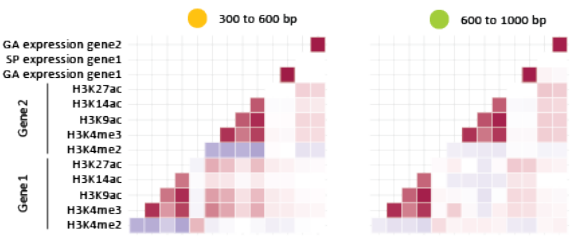

1000 to 2000 bp

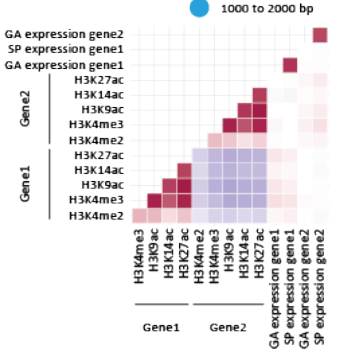

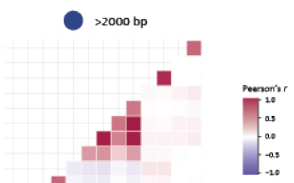

Fig. S8 Correlations of transcript abundances and histone PTM signals for divergently transcribed pairs of genes. a Pairwise comparisons of transcript abundances (TPM) and signal for the five TSS-localised histone PTMs for pairs of divergently transcribed genes (gene 1 and gene 2). b Pearson correlation scores for comparisons of transcript abundances (TPM) and signal for the five TSS-localised histone PTMs for pairs of divergently transcribed genes. Histone PTM signals were measured for the regions $500 \mathrm{bp}$ downstream of each TSS. The schema in Fig. 5a indicates the relative organisation of gene 1 and gene 2. 


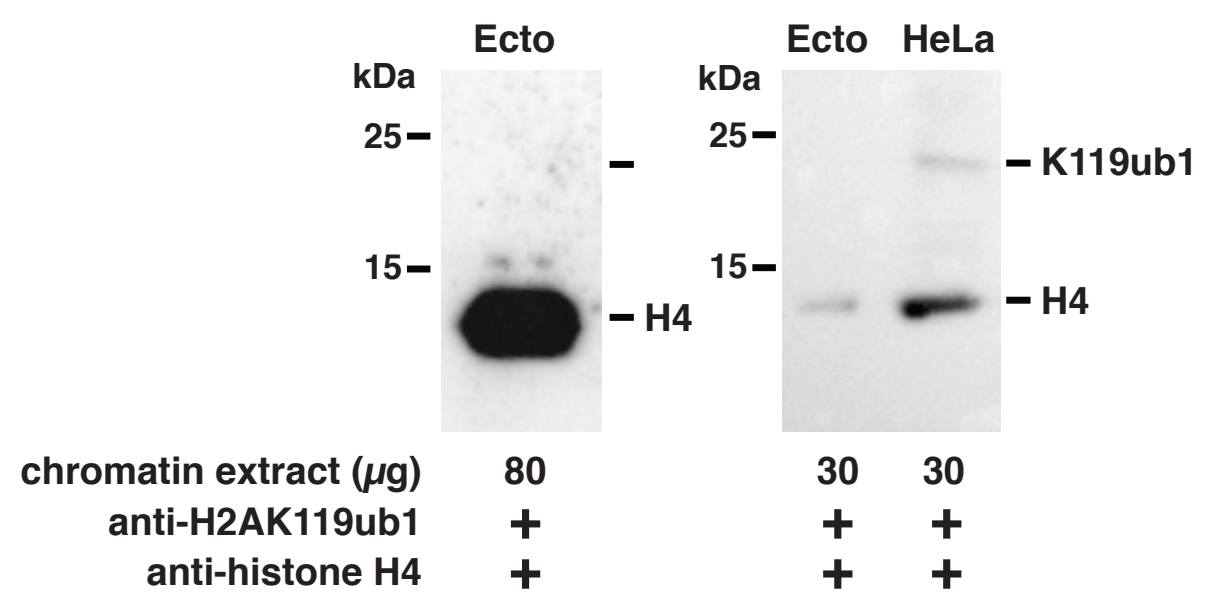

Fig. S9 The histone PTM H2AK119ub1 was not detected in Ectocarpus. H2AK119ub1 (K119ub1) was detected in a human HeLa cell chromatin extract (HeLa) as a positive control. Histone H4 (H4) was detected as a loading control. The Ectocarpus chromatin extracts (Ecto)

1171 were the same as those used for the immunoblots shown in Figure S3. 


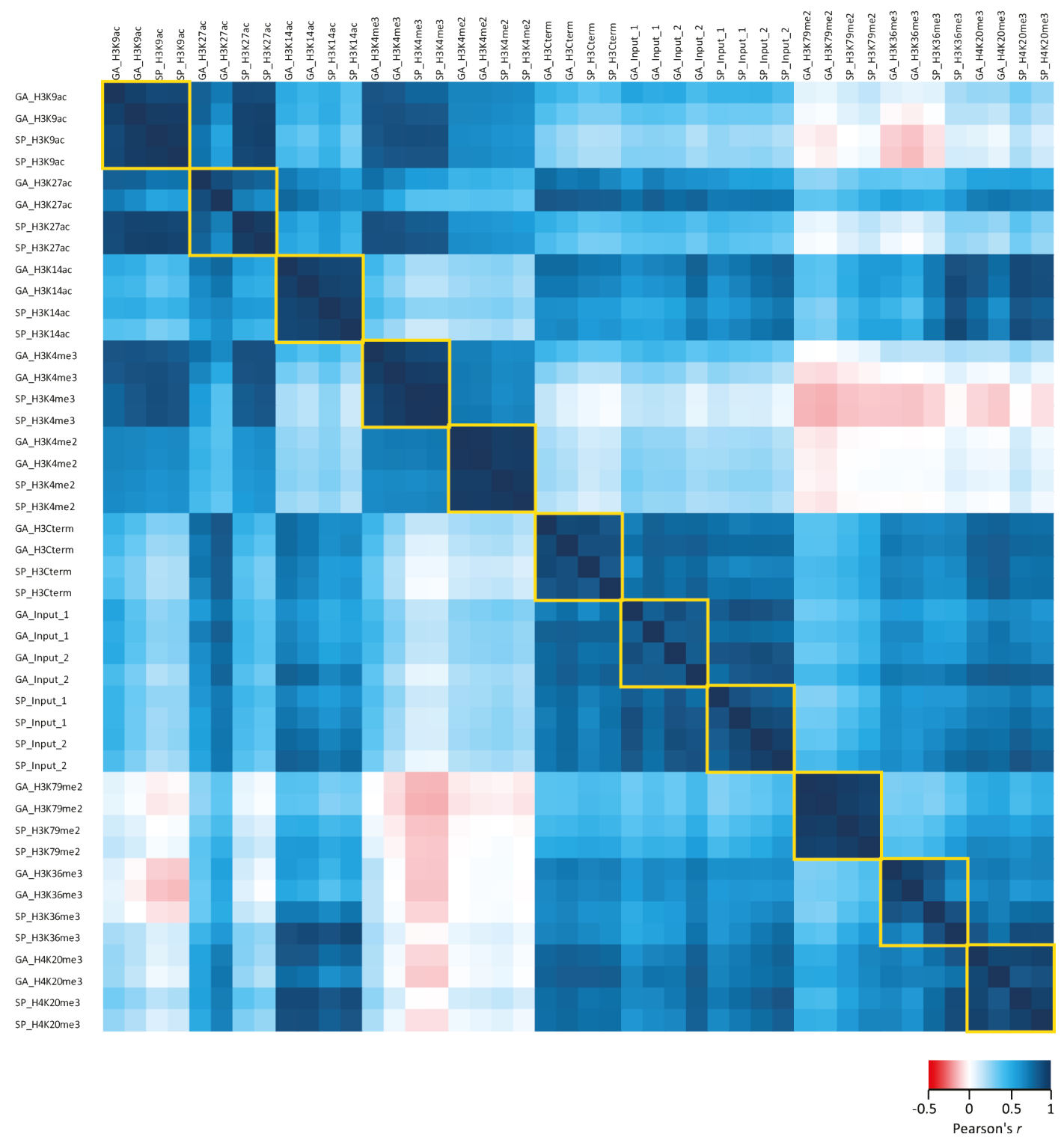

Fig. S10 Pearson correlation scores for comparisons of the genomic distributions of ChIP-seq gametophyte generations. 